\title{
A review of applications of the six-step method of systematic conservation planning
}

\author{
by Yolanda F. Wiersma ${ }^{1, *}$ and Darren J.H. Sleep²
}

\begin{abstract}
Systematic Conservation Planning (SCP) is an approach to protected areas planning that follows a step-by-step process. Recent reviews have examined the use of key "biogeographic-concepts", but an assessment of their use or effectiveness has not been done. We conducted a review of the literature on SCP to assess how the 6-step approach considers these concepts. Most of the 127 papers we reviewed varied in their application of SCP steps. Our findings suggest that protected areas plans are not effectively achieving conservation goals. Only six papers considered data uncertainty. Twenty papers used so-called "data free" conservation targets without clear rationales, and which have been shown to under-represent natural features. The median size of planning units applied ( $2500 \mathrm{ha})$ is too small to meet minimum area requirements for many species. We show how an examination of the variation in the ways that SCP is applied helps to identify best practices for achieving conservation effectiveness and efficiency. However, very few SCP efforts have been implemented, making it difficult to assess their effectiveness or efficiency in practice. Detailed examination of how SCP is implemented (perhaps focused on a specific region) can lead to a better understanding of how best to achieve large-scale conservation goals.
\end{abstract}

Key words: Systematic Conservation Planning, 6-step biogeographic-concepts, protected areas

\section{RÉSUMÉ}

La planification systématique de la conservation systématique (PSCS) consiste enest une approche méthode utilisée dans la planification des territoires protégés qui suit s’appuie sur une démarche séquentielle. Des études récentes se sont penchéesont étudié sur lemploi dess plus importants « « concepts biogéographiques » » clés, mais aucune évaluation de son leur utilisation ou de son leur efficacité n’a encore jamais été faiteréalisée. Nous avons dons effectué une revue de la littératureanalyse documentaire portant sur la PCS afin dévaluer comment cette approche en 6 étapes tient tenait compte de ces concepts. La plupart des 127 articles que nous avons étudiés parcourus affichaient montraient une certainegrande variabilité dans lutilisation des étapes de la PCS. Nos résultats laissent entendre voir que les plans pour ldes territoires protégés n’atteignent pas les objectifs de conservation. Seulement six articles ont abordé l'incertitude entourant les données. Vingt articles ont utilisé des objectifs de conservation soi-disantdits « « non rattachéssans à des données » et sans justification précise et qui se sont révélés àavérés sous-représenter les caractéristiques naturelles. La taille médiane des unités de planification étudiées (2 $500 \mathrm{ha}$ ) est trop petite pour répondre aux exigences de superficie minimale de plusieurs espèces. Nous indiquons montrons comment comment une étude de l'examen de la variation danse l'application de la PCS permet didentifier les meilleures pratiques qui contribueront à l'atteinte de permettant d'atteindre l'efficacité efficience et lefficacité efficience en matière de conservation. Cependant, il y a eu peu de bien peu de projets de PCS ont été mis en œuvrecomplets, ce qui rend difficile dévaluer une évaluation pratique de leur efficacité efficience ou de leur efficienceefficacité dans la pratique. Une étude détaillée sur la façon d'implanter la PCS (peut- être en se concentrant sur une région donnée) permettrait dobtenir une meilleure compréhension de la démarche à suivre pour atteindre les objectifs de conservation à grande échelle.

Mots-clés : planification de la conservation systématique, six étapes des concepts biogéographiques en six étapes, territoires protégés

\footnotetext{
${ }^{1}$ Department of Biology, Memorial University, St. John's, Newfoundland and Labrador, A1B 3X9, Canada ${ }^{\star}$ corresponding author: ywiersma@mun.ca

${ }^{2}$ National Council for Air and Stream Improvement, P.O. Box 1036, Stn B, Montreal, Québec, H3B 3K5, Canada
} 


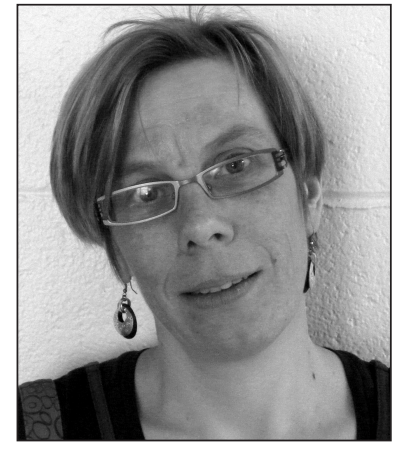

Yolanda F. Wiersma

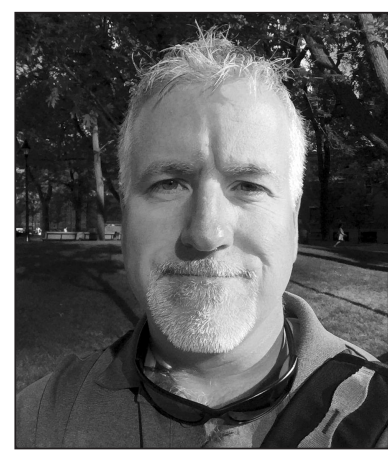

Darren J.H. Sleep

\section{Introduction}

Landscapes maintained and managed as protected areas are intended to protect special ecological spaces or values (watersheds, critical habitat for threatened species), or to act as reserves to maintain biodiversity (Duinker et al. 2010). In some cases, protected areas may have other uses as well, such as the preservation of natural or semi-natural benchmarks for contrast with developed areas (Arcese and Sinclair 1997), or the maintenance of landscape types that are difficult to maintain on intensely managed landscapes. In these cases, protected areas may be considered a complimentary land use to natural resource management such as forestry, agriculture or grazing. Protected areas, as well as other types of land use may also provide aesthetic, recreational or educational values (Dearden 1995).

The way in which protected areas are established to meet conservation objectives has evolved from its initial focus on the designation of single sites of exceptional aesthetic, recreation, or biodiversity value (Runte 2010). Systematic Conservation Planning (SCP) has emerged as an approach to identify sites for protected areas and facilitate decision-making with an emphasis on the use of protected areas as a key tool in biodiversity conservation. However, we contend that land-use planning for protected areas (SCP) is not as rigorous as planning within other natural resource sectors (e.g., forestry), mainly due to inconsistencies in the ways that key concepts and steps in SCP are applied. While some variation in application may be expected due to regional contexts, our concern is that inconsistencies can lead to misunderstanding between practitioners, lack of clarity on best practices, and reduced effectiveness and efficiency of conservation initiatives.

SCP concepts were popularized with the publication of a paper in Nature (Margules and Pressey 2000) and a special issue on the topic in Biological Conservation (Cowling and Pressey 2003), and resulted in a "period of expansion" of SCP (Kukkala and Moilanen 2013: 446). Based on these early concepts, Margules and Pressey (2000) outlined six key steps for SCP (Table 1). These were later expanded upon by others to provide details on the step of goal setting (Step 2; Tear et al. 2005) and to refine and expand the other steps (Gaston et al. 2002, Margules et al. 2002, Sarkar 2005, Wilson et al. 2005, Pressey and Bottrill 2009, Sarkar and Illoldi-Rangel 2010). The literature on SCP has proliferated in the past two decades (see Fig. 1 in Kukkala and Moilanen 2013).

Despite increased conservation literature on protected areas design, threats to biodiversity persist and losses continue (McKee et al. 2004), and recent papers have called for increases in protected areas globally (Venter et al. 2014, Larsen et al. 2015). Thus, consistency around how to best make decisions on the identification of priority areas for conservation is important. In their concluding paragraph, Kukkala and Moilanen (2013: 460) ask "Are the operational definitions of these concepts clear and applicable in realworld planning?" Our work is motivated by this statement. We conducted an in-depth review of 127 papers that document application of SCP concepts to assess whether and how application of SCP varies globally. Although variation in application is to be expected due to variation between sites (e.g., tropical vs. temperate), we were interested in whether there is variation due to lack of clarity in the way SCP steps and concepts are applied.

Although there is a large body of peer-reviewed literature on SCP, including several reviews (Justus and Sarkar 2002, Pressey et al. 2007, Sarkar 2012, Kukkala and Moilanen 2013) and a book (Moilanen et al. 2009), there has been little work comparing and contrasting how SCP is applied around the globe. SCP has been widely embraced, but the steps outlined by Margules and Pressey (2000) have not always been applied in the same ways. We are not aware of any systematic examination of which aspects of SCP (e.g., targets, study area and planning unit type/size, tools, methods) best achieve effective conservation outcomes (but see Van Teeffelen et al. 2012).

A thorough evaluation of the effectiveness of SCP is outside the scope of this review. Rather, here we conducted an assessment of the peer-reviewed literature to compare and contrast how the original six steps of SCP as outlined by Margules and Pressey (2000) have been operationalized around the world. Our review is not intended to comment on the utility of the original six steps themselves (which, as pointed out above, have been updated several times), but rather to examine the variety of ways in which the steps and underlying concepts have been interpreted and applied as a means to evaluate the way they are operationalized. We structured our review around the original six steps of SCP (Margules and Pressey 2000) although it is important to note that in realworld conservation planning these steps are not necessarily directional. We have listed the original six steps from Margules and Pressey (2000), and juxtaposed these with the key concepts from Kukkala and Moilanen (2013) that are pertinent to each step (Table 1). Thus, the purpose of this review is to compare and contrast how SCP steps have been applied in the real world, and to assess whether and how individual initiatives have addressed some of the uncertainties inherent in the application of each of the steps and key concepts. Specifically, we evaluated: (1) the number and type of conservation features used in SCP (along with the degree to which uncertainties in data and validity as surrogates were evaluated); (2) the different types of goals and targets used to inform SCP; (3) the types of evaluation strategies applied to assess existing protected areas; (4) the range of tools applied to carry out SCP; (5) the degree to which implementation strategies are documented; and, (6) how projects carry out evaluations of the effectiveness of SCP.

\section{Methods}

Terminology

In a recent comprehensive review of the SCP literature, Kukkala and Moilanen (2013) identified and examined 12 
Table 1.

\section{Systematic Conservation Planning (SCP) Steps} (Margules \& Pressey 2000)
Key SCP Concepts

(Kukkala \& Moilanen 2013)

for consideration
Findings from this Review

1. Compile data on the biodiversity of the planning region.

- Review existing data and decide on which data sets are sufficiently consistent to serve as surrogates for biodiversity across the region.

- If time allows, collect new data to augment or replace some existing data sets

- Collect information on the localities of species considered to be rare and/or threatened in the region (these are likely to be missed or under-represented in conservation areas selected only on the basis of land classes such as vegetation types).
- The conservation plan will be limited at the outset by how comprehensive the biodiversity data are.

- It will be important to consider how representative the features for which there are data are of the wider suite of biodiversity features.

- Data on species that may be under threat might be of particular relevance.
- Most plans use whatever data are available without a rigorous evaluation of their ecological importance.

- Species are often presumed to be surrogates (i.e., representative of) for other elements of the ecosystem, without sufficient testing.

- Common features and species are used more in planning than rare ones; where rare species are included, they are not always threatened.

2. Identify conservation goals for the planning region.

- Set quantitative conservation targets for species, vegetation types or other features (for example, at least three occurrences of each species, 1500 ha of each vegetation type, or specific targets tailored to the conservation needs of individual features). Despite inevitable subjectivity in their formulation, the value of such goals is in their explicitness.

- Identify qualitative targets or preferences (for example, as far as possible, new conservation areas should have minimal previous disturbance from grazing or logging).

3. Review existing conservation areas.

- Measure the extent to which quantitative targets for representation and design have been met my existing conservation areas.

- Inclusion of existing poor-quality conservation areas may carry high cost

- Identify the imminence of threat to under-represented features such as species or vegetation types, and the threats posed to areas that will be important in securing satisfactory design targets.
- An evaluation of the adequacy of targets for achieving goals is necessary.

- Targets are usually devised to ensure representation of the biodiversity features for which there are data.
- Targets are often data-free and not evaluated as to whether they are adequate for the region.

- The literature suggests that there is no universal target; goals and targets should be specific to each project.

4. Select additional conservation sites.

- Regard established conservation areas as "constraints" or focal points for the design of an expanded system.

- Identify preliminary sets of new conservation areas for consideration as additions to established areas. Options for doing this include reserve selection algorithms or decision-support software to allow stakeholders to design expanded systems that achieve regional conservation goals subject to constraints such as existing reserves, acquisition budgets, or limits on feasible opportunity costs for other land uses.
- Algorithms and decision-support software often incorporate principles of complementarity.

- Selection processes are designed to maximize efficiency.
- There are many tools and strategies to carry out conservation planning; most are based on concepts of efficiency and complementarity.

- A comparison of software packages (of which there are several) was beyond the scope of the paper.

- Modern computing has rendered moot the debate between using heuristic vs. optimization algorithms. 
Systematic Conservation Planning (SCP) Steps (Margules \& Pressey 2000)
Key SCP Concepts

(Kukkala \& Moilanen 2013)

for consideration
Findings from this Review

5. Implement conservation actions

- Decide on the most appropriate or feasible form of management to be applied to individual areas (some management approaches will be fallbacks from the preferred option)

- If one or more selected areas prove to be unexpectedly degraded or difficult to protect, return to stage 4 and look for alternatives.

- Decide on the relative timing of conservation management when resources are insufficient to implement the whole system in the short term (usually).

\section{Maintain the required values of conservation areas}

- Set conservation goals at the level of individual conservation areas (for example, maintain seral habitats for one or more species for which the area is important). Ideally, these goals will acknowledge the particular values of the area in the context of the whole system.
- The degree of irreplaceability of particular sites should also inform prioritization.

- How easy it is to implement the conservation plan may depend in part on the inherent flexibility of the plan.
- There is very little description of plans which have been fully implemented.

- Implementation requires thinking about dimensions beyond scientific/ecological ones; including economic, social and political contexts.
- With long-term monitoring, it will • be possible to evaluate the effectiveness of the conservation network.
There are no descriptions of case studies where conservation plans have been implemented and monitored for their effectiveness.

- Implement management actions and zonings in and around each area to achieve the goals.

- Monitor key indicators that will reflect the success of management actions or zonings in achieving goals. Modify management as required.

core concepts of SCP (adequacy, comprehensiveness, representativeness, representation, complementarity, threat, vulnerability, efficiency, effectiveness, irreplaceability, replacement cost, flexibility) and suggested that while some are well-defined, others have conflicting definitions and usage in the literature. Thus, for clarity, we outline the meaning of terms as we use them in this review. When we refer to the "design" of protected areas networks, we refer to a formalized strategy or method to identify potential protected areas within a larger region (where "region" can refer to an individual country or natural or political subdivisions thereof). "Networks" refers to multiple protected areas (also referred to as the "network set") within a defined spatial region that either have physical or ecological connectedness (to facilitate flow of organisms and processes) and/or are designed in concert with each other within a region to concomitantly meet a larger conservation goal.

We adopt terminology more common in the Australian and South African literature on SCP and also used in Margules and Pressey (2000) which differs from terms used elsewhere (Groves 2003). Thus we use "goal" to mean the overall purpose of the conservation effort. In this case, the goal of all the SCP efforts discussed in the reviewed papers is to achieve biodiversity conservation; however, in individual papers the goal may be more specific, such as the conservation of threatened vertebrates or of endemic plants within a defined region. We use the term "conservation feature" to mean the entity that is the focus of conservation in a particular study; other papers, e.g., Groves 2003, use the term "biodiversity target" or "conservation target" to mean the entity of conservation interest, and Margules and Pressey (2000) refer to such data as "surrogates for biodiversity". Here "conservation target" refers to the desired level of conservation in the final reserve network. This can be expressed in a variety of ways (see discussion of Step 2 below). Common examples of conservation targets are specified minimum number of populations of the conservation feature, or a minimum level of representation of particular habitat types.

\section{Literature Search}

To carry out our analysis we conducted a literature search using the Scopus database. We searched the following search strings sequentially: "systematic conservation planning", "reserve design" OR "protected area design", and "reserve network". The sequential search yielded some duplicate findings which were removed, but searching "reserve network" yielded a different set than "reserve design" and thus this sequential search was necessary. We also searched the terms "reserve" OR "protected area" in combination with (i.e., logical operator AND) the terms "hotspots" and "gap analysis", since these terms represent early strategies applied in SCP. We did not search on the above terms without quotes, (although this yielded a larger number of articles, for example a search on "systematic conservation planning" without quotes yielded over 500 articles) because many of these were about conservation and/or planning, and not specifically on 
SCP in the sense in which we wanted to focus. We also did not choose to use the names of specific tools (e.g., "Marxan" or "Zonation") as keywords in our initial search. Although searches on these terms yielded a large number of articles, our goal was to assess the way SCP strategies were applied, not specific tools. We conducted forward and back citation searches to find additional articles and included papers from around the world. We selected articles that described realworld data (that is, simulation modelling and conceptual papers were excluded) and met at least one of the following criteria of SCP: 1) the plan included quantitative targets; 2) the focus of the paper was on improving methods for identifying and/or establishing networks of reserves for conservation; 3 ) the paper identified a list of conservation features; and, 4) there was some sort of systematic approach (e.g., an algorithm, an optimization tool, complementarity principles) to selecting sites. Theoretical papers that used hypothetical data for the purposes of illustrating principles of SCP were not included in the database. We also excluded reviews of SCP concepts, critiques of previous work, and meta-analyses. We did not consider papers that only discussed effectiveness or management of existing protected areas. We further excluded papers dealing with conservation planning in freshwater and marine areas. Freshwater and marine conservation planning is an important and growing area of work. However, the terrestrial and aquatic/marine environments differ dramatically both biophysically and in terms of political jurisdictions, which means that approaches to planning and implementation will be very different than in terrestrial realms (Hansen et al. 2011). Although we are using the Margules and Pressey (2000) paper to frame this review, we searched for papers from all available dates (up to December 31, 2013), since the literature on systematic conservation planning dates back to the 1980s (Kukkala and Moilanen 2013). We did not include any 'grey literature', even though many organizations (e.g., the Nature Conservancy) publish conservation planning documents. It can be difficult to get a full representation of the grey literature from academic search indices, and our review is intended to be illustrative of the variation of applications of SCP concepts rather than comprehensive. Despite these limitations, we feel the sample of papers is sufficiently representative to allow us to make broad inferences.

Our final database contained 127 papers (see supplementary material S.1 available only in the on-line version of this paper). We read each paper closely to extract data relevant to the steps in SCP (Table 1). Where the information was available, we recorded data on the type and size of the study area, the type and size of the planning units, the species or features for which conservation areas were being planned, the type of conservation targets applied, and the tools used. Not all papers included details on all of the data in which we were interested, and we were not able to follow up with individual authors to try to obtain missing data. We included data from all studies which were carried out in the same location, since in some cases there were subtle differences in aspects of each study (e.g., method, biodiversity target). Some of the papers we reviewed contained information from studies in multiple locations; in these cases we used data from all study sites.

Table 2. Types of data used as conservation features in 127 papers in literature review. The total of the count column is greater than 127 because some papers made use of multiple sets of conservation features (e.g., birds and mammals).

\begin{tabular}{|c|c|c|c|}
\hline Conservation Feature & $\begin{array}{c}\text { Mean } \\
\text { number of } \\
\text { species/ } \\
\text { features }\end{array}$ & $\begin{array}{c}\text { S.D. } \\
\text { species/ } \\
\text { features }\end{array}$ & $\begin{array}{c}\text { Count } \\
\text { (number } \\
\text { of papers) }\end{array}$ \\
\hline \multicolumn{4}{|l|}{ Broad species variables } \\
\hline species in a specific habitat ${ }^{\mathrm{a}}$ & 1095 & 2248.5 & 5 \\
\hline invertebrates ${ }^{\mathrm{b}}$ & 158 & 137.1 & 3 \\
\hline vertebrates ${ }^{\mathrm{b}}$ & 799 & 1415.5 & 6 \\
\hline plants $^{c}$ & 1387 & 2173.5 & 23 \\
\hline listed species ${ }^{\mathrm{d}}$ & 185 & 308.1 & 18 \\
\hline \multicolumn{4}{|c|}{ Specific groupings of species variables (taxonomic classes) } \\
\hline Amphibians & 115 & 156.1 & 7 \\
\hline Birds & 227 & 229.2 & 26 \\
\hline Fish & 46 & $\mathrm{n} / \mathrm{a}$ & 1 \\
\hline Herptiles & 88 & 62.2 & 2 \\
\hline Mammals & 387 & 1158.6 & 28 \\
\hline Reptiles & 19 & 17.4 & 5 \\
\hline \multicolumn{4}{|c|}{ Highly specific groups of species variables (taxonomic groupings) } \\
\hline Bats & $4 \quad$ & $\mathrm{n} / \mathrm{a}$ & 1 \\
\hline Beetles & 127 & 63.3 & 3 \\
\hline Bryophytes & 47 & $\mathrm{n} / \mathrm{a}$ & 1 \\
\hline Butterflies & 122 & 131.8 & 7 \\
\hline Carnivores & 4 & $\mathrm{n} / \mathrm{a}$ & 1 \\
\hline Dragonflies & 367 & 315.1 & 4 \\
\hline Molluscs & 47 & $\mathrm{n} / \mathrm{a}$ & 1 \\
\hline Raptors & 3.5 & 3.5 & 2 \\
\hline Salamanders & 11 & $\mathrm{n} / \mathrm{a}$ & 1 \\
\hline Trees & 367 & 304.3 & 4 \\
\hline \multicolumn{4}{|l|}{ Environmental variables } \\
\hline sites of interest & 1963 & 3322.9 & 3 \\
\hline environmental parameters & 16 & 3.0 & 4 \\
\hline vegetation classes/land cover & 204 & 444.9 & 33 \\
\hline Wetlands & 5 & $\mathrm{n} / \mathrm{a}$ & 1 \\
\hline
\end{tabular}

\footnotetext{
aThis includes paper that examined for example "beach species", "fen species" and included plants and animals.

b"Invertebrates" and "Vertebrates" indicates papers that made uses of a suite of species from different classes or families; rather than a specific subgroup (e.g., butterflies, birds).

c"Plants" indicates papers that made use of a wide range of plant species, or in some cases specific species/subgroups (e.g., orchids)

dListed species" indicates papers where the species used for analysis was listed (e.g., IUCN Red-List, or national species-at-risk status) or otherwise identified as "at risk" of extinction, regardless of taxa). Some of these were further subset into the following taxonomic groups: amphibians (1), listed birds (3), dragonflies (1), herptiles (1), invertebrates (1), mammals (2), plants (3) and vertebrates (1). These are not double-counted in

the table and are summarized in the text of the paper.
} 


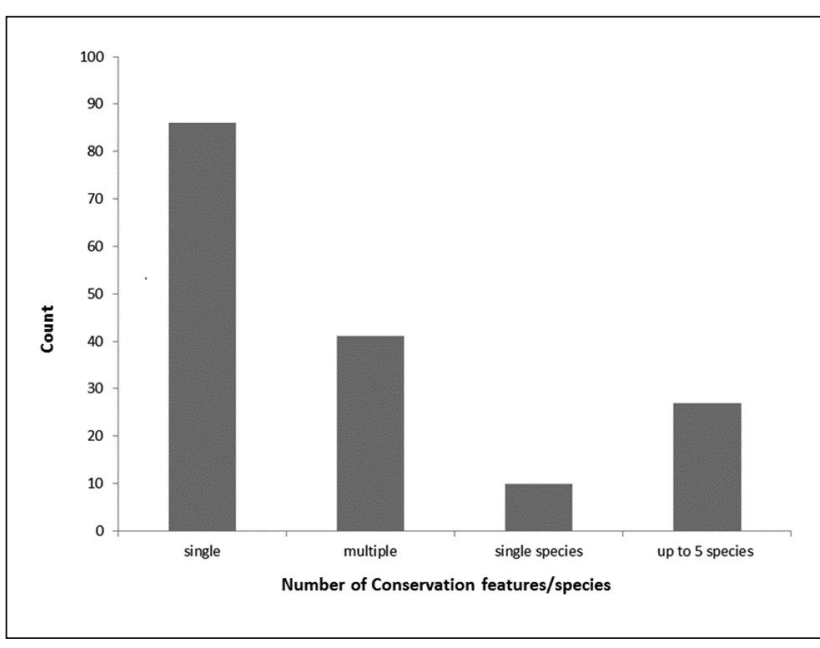

Fig. 1. Count of 127 papers based on the number of conservation features (e.g., landcover type or ecosystem) or species included in the study.

\section{Results}

\section{Conservation features}

Step 1 (Margules and Pressey 2000) outlines the critical role that data play in SCP. The conservation features (i.e., surrogates for biodiversity) used in the papers we surveyed fall into two broad categories: species and environmental variables (Table 2). The latter can include biotic data such as vegetation communities or land cover types as well as abiotic data such as elevation, productivity, and climate which are commonly used as proxies for ecological regions and/or ecosystems (Margules and Pressey 2000, Williams et al. 2002). Kukkala and Moilanen (2013) stress that comprehensiveness of the data considered is important. Individual research papers varied in their comprehensiveness (Fig. 1). Of the 127 papers, 86 used a single feature category, while 41 were more comprehensive and made use of more than one conservation feature category. In addition, while many papers used a broad taxonomic group from their region for each particular conservation feature category (e.g., all vascular plant species), some papers used more narrowly defined (yet highly diverse) taxonomic groups as conservation feature categories (e.g., beetles, butterflies), and yet others used a very small set of species within a particular category. Ten papers developed SCPs using only a single species and an additional 27 papers used five or fewer species/elements (Fig. 1).

Only six papers explicitly addressed any aspects of uncertainty in species distribution data used, such as spatial or temporal accuracy (Flather $e t$ al. 1997, McCarthy et al. 2006, Chen and Bi 2007, Gove et al. 2008, Carvalho et al. 2010, Hermoso and Kennard 2012). Of the 127 articles reviewed, vegetation/land cover classes were the conservation feature most commonly used, followed by mammals, birds and plant species (Fig. 2). Vegetation/land cover likely was the most common

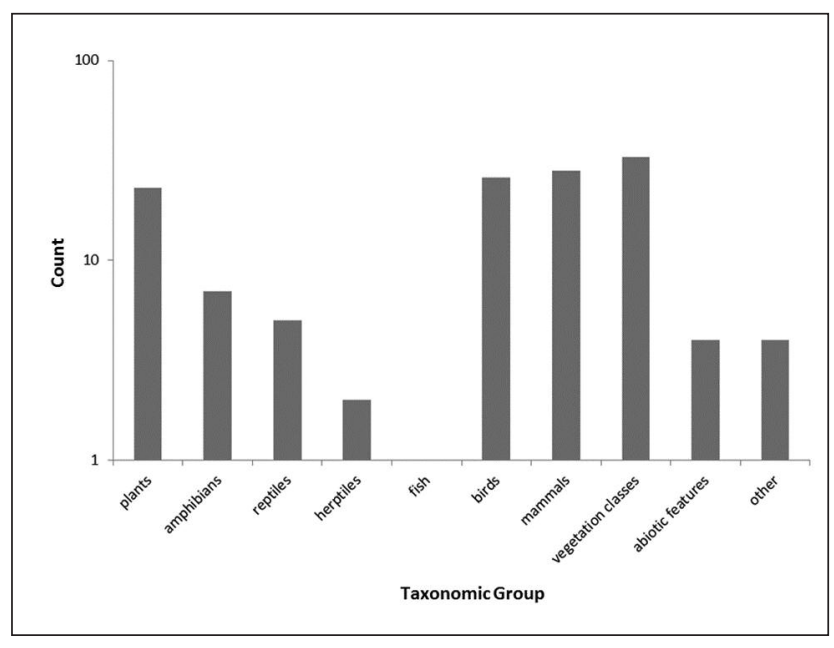

Fig. 2. Count of number of different species, by different taxonomic groupings, which are included in 127 papers on systematic conservation planning.

because it can be obtained for a broad region via remote sensing, while using plant species (or other species groups) requires on-the-ground surveys, although some type of satellite data can carry a high cost.

\section{Goals and targets}

Step 2 in Margules and Pressey (2000) emphasizes the importance of goals and targets. Eighty-seven of the papers used quantitative targets in SCP; of these, 20 used a blanket percentage target, ranging from $1 \%$ to $75 \%$ of total land area (mean 20\%, s.d. 22\%). These are examples of 'data-free' targets (Svancara et al. 2005), in that they are not based on any particular empirical investigation and so likely are not adequate. Six papers used the well-known "10\%" or " $12 \%$ " targets that came out of the World Parks Congress (McNeely and Miller 1984) and the Brundtland Commission (WCED 1987). Thirteen papers we reviewed focused on maximizing representation of species and/or features with a minimum amount of area. The majority of these (8) aimed to have every species represented at least once, while three set targets of intervals
Table 3. Minimum, maximum, mean and median size (in hectares) of planning units by type used in 127 papers on systematic conservation planning.

\begin{tabular}{lccccc}
\hline $\begin{array}{l}\text { Type of } \\
\text { planning unit }^{\mathbf{a}}\end{array}$ & Minimum & Maximum & Mean & Median & Count $^{\mathbf{b}}$ \\
\hline Ecological $^{\mathrm{c}}$ & 0.4 & 190000000 & 12000000 & 2750 & 17 \\
Hexagon & 10 & 64000 & 13031 & 750 & 8 \\
Square & 0.25 & 1300000 & 139425 & 6500 & 33 \\
Other polygon $^{\mathrm{d}}$ & 0.2 & 899100 & 56040 & 1600 & 24 \\
Pixel & 0.25 & 1826400 & 151838 & 552 & 27
\end{tabular}

aplanning units are defined as the units of analysis used as "building blocks" in the site prioritization.

${ }^{b}$ Counts sum to a number larger than the number of papers represented in the table, since some papers presented results with different types and sizes of planning units. As well, the number of papers represented here is different from that in other tables because of differences in details on study area and planning unit size that were provided in individual papers.

${ }^{\mathrm{c} E c o l o g i c a l l y-d e f i n e d ~ p l a n n i n g ~ u n i t s ~ i n c l u d e ~ n a t u r a l ~ p a t c h e s ~ o f ~ h a b i t a t ~(e . g ., ~ f o r e s t ~ s t a n d s) ~ o r ~ p h y s i o g r a p h i c ~ u n i t s ~}$ (e.g., watersheds).

d"Other polygon" refers to irregular polygons that are not defined ecologically, and may include counties, existing protected areas, or land ownership parcels. 
Table 4. Summary of tools used in Systematic Conservation Planning based on a survey of 72 papers that made use of computer software or analytical techniques (indicated by italics) ordered from most to least frequent. For specific software packages, the source is given, if available. There are multiple software packages that can be used for optimization, statistical and GIS analysis, so these are listed as n/a.

\begin{tabular}{lcl}
\hline Tool & Count $^{\mathbf{a}}$ & \multicolumn{1}{c}{ Source } \\
\hline Marxan & 19 & $\begin{array}{l}\text { University of Queensland, } \\
\text { Australia }\end{array}$ \\
statistical models & 14 & $n / a$ \\
Zonation & 10 & University of Helsinki \\
optimization algorithms & 9 & $n / a$ \\
$\quad$ linear and integer) & & \\
C-Plan & 7 & Environmental Decisions Group \\
ResNet & 4 & University of Texas at Austin \\
GIS-based & 3 & n/a \\
CONSERVE & 2 & no longer available \\
WORLDMAP & 2 & Natural History Museum, UK \\
CODA & 1 & no longer available \\
Decision-analysis & 1 & $n / a$ \\
DIVERSITY & 1 & no longer available \\
GARP & 1 & no longer available \\
LARCH & 1 & Wageningen University \\
MinPatch & 1 & Durrell Institute of Conservation \\
RESERVE & & and Ecology \\
TARGET & 1 & See Briers RA (2002) \\
\hline
\end{tabular}

${ }^{a}$ Count indicates the number of papers which specified use of the tool and sums to a larger number than the sample of papers because some papers presented work using more than one tool.

from 1-6 representations of each species (Margules et al. 1988, Rodrigues et al. 2000a, Bonn and Gaston 2005) and two suggested representation should be as high as 10 instances (Heikkinen 2002, Simaika and Samways 2009).

\section{Evaluation of existing protected areas}

Most studies did not detail how existing protected areas were assessed (Step 3; Margules and Pressey 2000), so we used planning units described in SCP methods as indicative of what authors thought were adequate requirements for a single protected area. The median size of the planning units in our literature review (2500 ha) was much smaller than what most of the literature recommends for ecological viability (Table 3). Planning units were ecologically-defined (e.g., watersheds, catchments) in only 17 of the papers (Table 3), and the others were squares, pixels, or hexagons (and hence not likely to reflect realistic or effective reserve boundaries).

\section{Tools applied in SCP}

The addition of new conservation areas is Step 4 in Margules and Pressey (2000) and a large variety of software tools have been developed to carry out SCP. Nearly all of these incorporate the concepts of complementarity and efficiency.
Seventy-two papers reviewed described a particular software tool (Table 4), the majority of which were Marxan, C-Plan, Zonation, and optimization algorithms (linear or integer programming).

\section{Implementation plans}

Only seven of the papers contained conservation plans that were at least partly implemented (or expressed intent to do so), which is step 5 in Margules and Pressey (2000). In our review, 19 papers explicitly included social and/or economic factors in their analysis. In papers that consider economic aspects of reserve design, costs are often simplified in terms of land area without accounting for variation in real estate prices. Others model trade-offs, in terms of other benefits such as alternative land uses, identify areas that are productive for forestry or other activities (Faith and Walker 2002). We are aware of only two papers where cost-benefit trade-offs included real-world estimates of net-present value (NPV) of forest harvests as a potential cost to a conservation plan (Perhans et al. 2008, Schnider et al. 2010).

\section{Evaluation of effectiveness}

Only seven of the papers actually documented any kind of systematic conservation plan that was at least partially implemented or expressed intent to do so. None included a comprehensive assessment of how well the plan achieved stated goals. Thus, we cannot evaluate the operationalization of this step in detail. Margules and Pressey (2000) emphasize that this final $\left(6^{\text {th }}\right)$ step is of fundamental importance, yet we could not find examples that illustrate how this step is carried out.

\section{Discussion}

Below we provide additional discussion of the results of our literature survey of the six steps in SCP as well as recommendations for practitioners considering implementing SCP.

Step 1: Compile data on the biodiversity of the planning region Of the conservation features chosen, mammals were the most frequent taxonomic group and the second-most common conservation feature after vegetation categories (identified using remotely-sensed data). This is not surprising since mammals are large, charismatic, and well-studied. Mammals may also serve as area-sensitive umbrella species (see discussion on the use of surrogate species below). Birds are the third most prominent group as they are often well-surveyed given the levels of amateur birders and the existence of long-term data sets across broad spatial extents (Sullivan et al. 2009).

The variation in the number of conservation features used across all papers indicates that comprehensiveness of data was variable, although it is obviously impossible to have data for all biodiversity or conservation features within a region (Kukkala and Moilanen 2013). Thus, it is important to know how well the conservation features used in SCP act as surrogates for biodiversity patterns. In many cases researchers are constrained by available data and thus forced to use limited sets of conservation features, which may or may not affect representativeness. In other words, if the conservation features used are good surrogates for biodiversity, then biodiversity will be well represented within the resulting conservation network. In our review, only 34 papers explicitly indicated that the species used in the SCP was serving as some sort of 
surrogate species (a term used to collectively describe keystone, indicator, focal, flagship, and umbrella species; for a review see Caro and O'Doherty 1999). However, only a handful of the 34 papers that used surrogates assessed the effectiveness of these in the context of their particular reserve design. In East Africa, Caro (2003) found that large mammals were effective umbrella species, and across Canada, Warman et al. (2004) found that richness of one taxonomic group (e.g., birds, mammals, reptiles, amphibians) was well-correlated with that of others. However, the utility of surrogate species has been postulated to be highly scale-dependent. For example, some authors have found surrogates to be ineffective in small areas (Caro et al. 2004), but effective in larger areas if minimum representation of the surrogate was met (Garson et al. 2002). Effectiveness as a surrogate may also vary across background taxa (Roberge et al. 2008). In a comprehensive review of 575 surrogacy tests from 19 studies, Rodrigues and Brooks (2007) evaluated the effectiveness of protected areas designed using surrogate species data for representing target taxa and found a positive but weak surrogacy effect. They found a number of papers where surrogacy was shown not to be effective, but also a great deal of variation in terms of which taxonomic group were more effective surrogates, and how surrogacy was defined (Rodrigues and Brooks 2007).

Many SCPs use range map data which delineate "extent of occurrence" as opposed to "area of occupancy" (Gaston and Fuller 2009). Species distribution data carries uncertainties along different dimensions of data quality, including accuracy, precision, and timeliness. For example, both extent of occurrence and areas of occupancy maps can have limitations (Williams et al. 2002, Fleishmann et al. 2006, Rondinini et al. 2006) due to errors in species identification, sampling biases (e.g., over representation of areas near roads; see Williams et al. 2012) and temporal gaps. Such errors and limitations have been shown to affect conservation planning and assessment (Habib et al. 2003, Gaston and Fuller 2009, Loehle and Sleep 2015). Of the six papers that addressed any aspects of uncertainty in the data (Flather et al. 1997, McCarthy et al. 2006, Chen and Bi 2007, Gove et al. 2008, Carvalho et al. 2010, Hermoso and Kennard 2012), all found that outcomes were sensitive to variations in data quality. Sensitivity analyses are a highly recommended step to assess how plans respond to variation in data in order to increase confidence in the final product.

A further consideration when selecting conservation features should be the threats to species or landscapes (Margules and Pressey 2000, Deguise and Kerr 2006, Kukkala and Moilanen 2013). Within our database, 18 papers made use of threatened species in conservation planning (Table 2). When considering rare, threatened and listed species, it is important to consider the reasons behind species rarity. Some species are naturally rare and thus may not necessarily need to be prioritized in conservation strategies (Drever et al. 2012, Strittholt and Leroux 2012). It is also important to distinguish between assessing threats of extinction to rare species and identifying species that are conservation priorities but may or may not actually be threatened (e.g., "listed species"; Mace and Lande 1991). Further, when conservation planning happens within politically bounded regions, species may be identified as rare because they are occurring at the edge of their range (Drever et al. 2012). Thus SCP within politically-bounded regions may inflate the importance of some rare species that may be abundant elsewhere, as was demonstrated for birds in South Africa (Rodrigues and Gaston 2002). Of the papers we reviewed, 110 clearly defined the study region (the rest simply specified an approximate region); of these 53 used an ecologically-defined study region and 57 a politically-defined one.

\section{Recommendations}

Care should be taken when choosing conservation features. If features are chosen to be surrogate species, there should be some certainty about what they are a surrogate for, and whether they are an effective surrogate across the study region. Species or environmental features should not be included in the SCP just because data are available; if these have little ecological relevance, then the resulting conservation network will not be very relevant for conservation.

\section{Step 2: Identify conservation goals and targets for the planning region}

Identification of conservation goals is a key step in SCP. Indeed, Tear et al. (2005) expanded on this single step to develop a list of standards and principles for goal setting. Margules and Pressey (2000) outline some examples of conservation goals such as minimum numbers of occurrences of each species or minimum conserved area. To ensure conservation goals are achieved, adequate quantitative and operational targets should be selected (Kukkala and Moilanen 2013). However, evaluating adequacy of targets is complex. Not surprisingly, data-free percentage targets (expressed as a percentage of the target region's land area) were the most commonly used. These are popular with policy-makers and environmental groups because they offer a clear objective and can be easily measured (Noss et al. 2012). However, the risk with data-free targets is that the amount advocated may either be inadequate to meet biodiversity conservation objectives, or inefficient by conserving amounts far in excess of what is needed. In the 1990s, a World Wildlife Fund-led campaign advocated a $12 \%$ target for protection of lands within Canada (Hummel 1995); more recently environmental groups have suggested that the targets should be closer to $50 \%$ of total land area (CPAWS 2008, Badiou et al. 2013, Wells et al. 2014). The $50 \%$ target has been advocated by Locke (2013) who based his evidence on an editorial by Noss et al. (2012). However, the percentage target data presented in Noss et al. (2012) varies widely, and even data from individual studies have large confidence limits around their estimate. There is no empirical evidence to support the claim that any fixed percentage of land target is sufficient to adequately conserve biodiversity. Svancara et al. (2005) reviewed 159 articles that proposed conservation targets and found that the "data-free" (or policydriven) targets were generally smaller than those based on empirical analysis.

Evidence-based targets (those that emerge from an assessment of the conservation requirements for a given suite of species in a given region) range from 33\%-99\% of total land area (Margules et al. 1988, Ryti 1992, Noss 1993, 1996; Saetersdal et al. 1993, Soulé and Sanjayan, 1998, Svancara et al. 2005, Noss et al. 2012). These targets aim to achieve representation of the full suite of biodiversity in a region. It is clear, however, that there is a great deal of uncertainty in the literature as to what an appropriate target value should be (Noss et al. 2012, Wilhere et al. 2012). It is likely that there is no universally-applicable percentage target to indicate how much 
protected area is "enough" to meet representation objectives for effective biodiversity conservation. Our review suggests that the value is context-dependent and is contingent on a number of issues, including scale (both grain and extent) and diversity levels (alpha, beta, and gamma), environmental variability, and the specific conservation goals and anthropogenic threats involved. Sensitivity of representation targets to conservation design was also demonstrated empirically by Justus et al. (2008) who suggested that targets should be based on functional relationships between the area for conservation and distribution of species. Only six of the papers we reviewed specified variable targets, with higher targets specified for the rare habitats and/or species.

Whether these targets for species representation are adequate to ensure population persistence is unknown; only one paper in our dataset tried to set targets for minimum numbers of individuals based on minimum viable population estimates (Kerley et al. 2003). The issue of persistence is one that has been extensively discussed in the literature, and which is not adequately addressed with representation targets (Rodrigues et al. 2000a, 2000b, Cabeza and Moilanen 2003, Kerley et al. 2003, Pressey et al. 2003, Solomon et al. 2003, Wiersma and Nudds 2006, Smith et al. 2010). If planning units are designed to meet minimum size thresholds for species persistence (Pressey and Logan 1998, Wiersma and Nudds 2006), or if the selection algorithms are modified to constrain sites to be of a minimum size and/or to be minimally fragmented (Moilanen and Wintle 2007, Smith et al. 2010), then representation and persistence goals might be adequate. However, only seven papers we reviewed (Pressey and Logan 1998, Gaston et al. 2002, McCarthy et al. 2006, Wiersma and Nudds 2006, Moilanen and Wintle 2007, Smith et al. 2010) used planning units that met some kind of minimum size criterion.

\section{Recommendations}

Although convenient, data-free conservation targets are not effective tools for conserving more complicated aspects of the environment such as species diversity and persistence, ecosystem representation, or biodiversity as a whole. The application of data-free targets may result in significant inefficiencies in conservation planning with largely unknown costs, both to society and to biodiversity, particularly where protected areas of higher order (IUCN classes I-IV) exclude future management options to redress the effects of natural disturbance or future potential effects of climate change. Although relatively simple to measure and promote, data-free targets do not lead to either a reduction in uncertainty or provide mechanistic explanations for relationships between land use activities and biological diversity, both of which are important to improve conservation planning over the long-term. Thus, data-free targets should be avoided.

\section{Step 3: Review existing conservation areas}

Margules and Pressey (2000) outline the need to review the extent to which conservation targets are met by existing protected areas. For example, one basic criterion with which to assess existing protected areas may be whether or not they are sufficiently large to conserve biodiversity in the long-term. The minimum size for a reserve is an important consideration, and can be estimated using principles from island biography theory (Gurd et al. 2001) or minimum viable popula- tion analysis (Landry et al. 2001, Reed et al. 2003, Kujala et al. 2011). Other approaches use species-area or species-density relationships to estimate minimum area requirements (Desmet and Cowling 2004, McCoy and Mushinksy 2007) or combine island biogeography principles with a landscape ecology approach (Harcourt et al. 2001, Parks and Harcourt 2002, Wiersma et al. 2004, Wiersma and Simonson 2010). Ecological processes can also be considered, such as minimum dynamic areas (Pickett and Thompson 1978, Hunter 1993, Leroux et al. 2007a, 2007b) that estimate the minimum area needed to ensure that essential ecological processes and disturbances can continue to take place unhindered.

Although much of the literature cited above is focused on determining requirements for a single site, incorporating these size guidelines into systematic reserve design will help to simultaneously address issues of representation and persistence (Gaston et al. 2002, McCarthy et al. 2006, Wiersma and Nudds 2006, Smith et al. 2010). The estimates of minimum reserve size are dependent on the specific region and taxa under consideration. Most research suggests these should be on the order of thousands or tens of thousands of square kilometres (100 000 to 1000000 hectares) to be ecologically effective in the event that the surrounding habitat matrix becomes completely altered, which is much larger than the median planning unit size (2500 hectares) found across papers reviewed here. The growing field of conservation biogeography (e.g., Mendenhall et al. 2014) can contribute usefully to analysing these issues.

Another criterion that should be considered when carrying out this step is the degree of vulnerability of existing protected areas. More vulnerable sites may carry higher inclusion costs in the long run (Kukkala and Moilanen 2013), especially if that vulnerability means they will likely need to be replaced after loss. However, if a highly vulnerable site is also the only occurrence of a particular rare feature, then it may be important for prioritization. One way vulnerability has been qualified is through the use of relative "intactness" of existing protected areas. "Intactness" is a term that is commonly related to both fragmentation and habitat loss, but is also a more holistic term that includes any alteration that is anthropogenic in nature, whether or not there is an ecological effect (NCASI 2011). Intactness, usually measured using a variety of satellite imagery, ancillary data, or expert opinion, may be considered as a factor inside existing protected areas (e.g., roads, tourist areas), or beyond the boundaries of protected areas, relating to the effects that the surrounding matrix may have on their ability to continue to conserve biodiversity (Parks and Harcourt 2002, Wiersma et al. 2004). However, using intactness as a criterion for protected area design is complicated, in that the concept encompasses a range of factors and considerations, both ecological and social, making it challenging to define an empirical metric for measurement (NCASI 2011).

\section{Recommendations}

Not all protected areas are equal. Existing protected areas should be rigorously evaluated against scientifically defensible (and regionally-appropriate) criteria for size, intactness and overall effectiveness for meeting conservation goals. If they are not effective, it may be inefficient to include them as part of a regional conservation area network. 


\section{Step 4: Select additional conservation areas}

There are a variety of tools and software employed to carry out SCP; most are based on considering sets of multiple-protected areas within a network simultaneously. This complementarity-based approach was developed with the idea that an effective reserve network was the set of protected areas that efficiently represented the full suite of biological and ecological features (Kirkpatrick 1983, Margules et al. 1988) by capturing as many features as possible within the smallest amount of land possible. Therefore, by being more efficient, more land is available for other types of use. Early work used heuristic algorithms to maximize network efficiency (Pressey and Nicholls 1989), but later advances in computing power gave rise to the use of optimization algorithms (Rodrigues et al. 2000c, Williams et al. 2004, Moilanen et al. 2009). The main debate in the literature on the issue of tools to apply to SCP has (until recently) hinged on the merits of using heuristic vs. optimization algorithms.

Heuristic algorithms follow a set of step-wise rules to iteratively add protected areas to a network set. Commonlyapplied rules are based on richness (i.e., sites with high species richness are selected first) or rarity (i.e., sites containing a high number of rare species are selected first). At each step, the principle of complementarity is applied. Thus, the next site selected is complementary to the ones already in the set in that it maximizes the number of new species/features added to the set. In this way, redundancies are avoided, and the set as a whole is as efficient as possible. Most papers we examined operationalized efficiency simply in terms of number of sites, but in reality sites may have different costs which can affect the likelihood of implementation (see step 5 below).

Proponents of optimization algorithms (also known as integer or linear programming techniques) argue that heuristic algorithms can only achieve a near-optimal solution (Rodrigues et al. 2000c) and thus are not maximally efficient. Optimization is either based on finding the minimum number of sites for a given number of occurrences (the "location set covering problem", Church et al. 1996; also known as the "species set covering problem", ReVelle et al. 2002) or on using a fixed amount of area, and optimizing the location of the set of sites to maximize the number of species or features captured (the "maximal covering location problem", Church et al. 1996; also known as the "maximal covering species problem", ReVelle et al. 2002). Until very recently, computing power limited the use of optimizing algorithms, since the large data sets commonly used in reserve design resulted in inefficient computing time to effectively assist planning (Strange et al. 2006). However, this is no longer an issue (Vanderkam et al. 2007, Billionnet 2011).

\section{Recommendations}

Many of the software packages listed in Table 4 were customdeveloped for a specific project. Thus, it is difficult to evaluate them against a suite of criteria (e.g., efficiency, user-friendliness, comprehensive, flexibility). MARXAN is the most widely used software and has various options for reserve selection algorithms. It also provides user-friendly output in the form of maps and graphs. Like most of the tools in Table 4, MARXAN is open-source, and has an active online community which provides peer-support. However, other software and techniques (e.g., statistical or GIS analyses) may function just as well in other contexts. Users should let their research question or management problem dictate which software package would be most effective rather than chose a tool because it appears to be the most widely used.

\section{Step 5: Implement conservation actions}

In theory, a key concept that can help inform decisions about which areas to prioritize is that of irreplaceability (Kukkala and Moilanen 2013). However, in practice we were unable to adequately assess how irreplaceability is operationalized in the context of implementing SCP, as only a few papers had any reference to implementation plans. Knight et al. (2008) document a similar lack of implementation and contend that it is due to a gap between knowledge and implementation. Protected areas establishment usually happens within government agencies, but sometimes can happen through Environmental Non-Governmental Organization-led initiatives (e.g., conservation easements). This can lead to challenges because the planning carried out without decision-makers may operate in a vacuum (Game et al. 2013). They identified this and five other common "mistakes" that can have a negative effect on the implementation of conservation plans. Additionally, implementation of protected areas once their locations have been identified through systematic conservation planning is a long process that also involves social, political, and economic dimensions, and some of the perceived gap may be due to delays within these arenas. Thus, there is a need to adopt a high degree of flexibility (Kukkala and Moilanen 2013). Although rarely done, it is possible to build the temporal aspect of lags between planning and implementation into SCPs to explicitly model flexibility (Meir et al. 2004, Spring et al. 2010). Some papers have model species and environmental dynamics to assess whether the static conservation scenario will be effective through time (Leroux et al. 2007a, Hartig and Drechsler 2008, Spring et al. 2010, Johst et al. 2011, Rubio et al. 2012), while others have suggested strategies for implementation (Knight et al. 2006a, 2006b). This sort of modelling can also be incorporated to model some of the uncertainties mentioned in steps 1-3 above, and assess the potential impact of these uncertainties on planning outcomes.

In the real world, conservation planning must be flexible enough take into account social and economic aspects and competing land uses. SCP was designed as a tool for assessing scenarios that can then be used to support decision-making across multiple sectors, land uses and social economic dynamics (Pressey et al. 2007, Kukkala and Moilanen 2013). Some researchers have suggested that, for real-world conservation planning, consideration of economic costs should be more important than biological assessments (e.g., Carwardine et al. 2010, Knight et al. 2011). Outside of the SCP literature, bio-economic trade-offs have been modelled to optimize NPV against different amounts of conservation reserves (Knoke and Moog 2005, Schneider et al. 2010) or to compare NPV of timber against ecosystem goods and services values of forest stands (Knoke and Weber 2006, Knoke et al. 2009, Schneider et al. 2010). Such methods might profitably be applied to SCP.

\section{Recommendations}

Implementation is the most difficult stage of SCP, since it requires interacting with decision-makers, land-owners and other stakeholders. The addition of research incorporating 
economic modelling or research on human dimensions may increase the ability to rigorously evaluate and defend a particular plan. This stage of SCP requires that practitioners have skills in collaborative decision making, negotiation and conflict resolution.

Step 6: Maintain the required values of the conservation areas Margules and Pressey (2000) emphasized that planning is an iterative process and does not stop once protected areas are in place. They point out that management of protected areas needs to be continually assessed to ensure they are maintaining conservation values. They also point out the importance of monitoring key indicators to ensure management effectiveness. However, in their review of key concepts, Kukkala and Moilanen (2013) suggest that effectiveness is not a completely straightforward metric. Jones et al. (2009) outline a conceptual approach to monitor land use and land cover in and around protected areas using remote sensing data. Joppa et al. (2008) provide a review of methods to evaluate success of protected areas in the tropics.

\section{Recommendations}

Standards for effectiveness are a necessary component of monitoring. These are not yet well-developed, and thus the focus of future research should be the development of standards and metrics for evaluating the effectiveness of both individual protected areas, but more importantly for systematic conservation plans and networks of protected areas. An examination of the grey literature might provide additional examples of implementation which could be informative.

\section{Conclusions}

SCP is an important tool in the development of effective and efficient protected areas which are an important aspect for helping to halt the loss of biodiversity globally, and maintaining the ecosystems, unique landscape features, and other societal values on the landscape. However, SCP is a relatively new endeavor. This novelty as a conservation tool is exemplified by the range and diversity of approaches and interpretations of basic SCP documented in this paper.

The limitations and uncertainties illustrated by this review do not mean that there is no room in SCP for qualitative or socially-derived criteria or features; indeed additional research on the utility of these strategies is needed. Relatively simple preservation of unique landscape features, archaeologically important areas, and other societal values remains an important aspect of SCP, and measuring the success of such preservation actions may be more straightforward. In some cases, a simple "yes or no" determination as to whether or not those values remain on the landscape will suffice. In contrast, some ecosystem functions and services (clean water, clean air), although difficult to conceptualize, remain important aspects for conservation even when empirically-derived relationships may be less well developed. Relatively arbitrary targets may suffice in the short-term, e.g., the 30\% equivalent clearcut area for watershed disturbance (Government of British Columbia 1996) while longer-term research efforts reduce uncertainty regarding the ecological effects of management. Further work is required to inform SCP initiatives regarding the cause and effect relationships between land uses and long-term ecosystem functions. As well, future research should develop tools and techniques that can model the impact that uncertainty in data, targets and design components can have on the final plan.

Overall, our review highlights the variation with which strategic conservation planning (SCP) steps are applied, as well as some of the uncertainty inherent in implementing these steps. This is not surprising, given the lack of clarity in the definitions of key SCP concepts described by Kukkala and Moilanen (2013). Efforts to standardize concepts and practices will lead to greater consistency in the application of actual on-the-ground conservation planning and will ultimately result in effective conservation of biodiversity.

\section{Acknowledgements}

Thanks to S. Leroux and several anonymous reviewers for helpful comments on earlier versions of this manuscript. Much of this work was completed while Yolanda Wiersma was a visiting researcher at the Institute of Forest Management at the Technical University of Munich, and she thanks colleagues there, particularly A. Hahn and T. Knoke, for helpful discussions. We thank M. Fahmy for his assistance in preparing the supplemental material. Funding for this work was provided by the National Council for Air and Stream Improvement, Inc., who also provided impetus for the review and helpful feedback (K. Vice).

\section{References}

Arcese, P. and A.R.E. Sinclair 1997. The role of protected areas as ecological baselines. J. Wildlife Manage. 61: 587-602. doi: $10.2307 / 3802167$.

Badiou, P. et al. 2013. Conserving the world's last great forest is possible: Here's how. International Boreal Conservation Science Panel Report. July 2013. Available from: http://borealscience.org/wp-content/uploads/2013/07/conserving-last-great-forests1.pdf [Accessed 12 July 2015].

Billionnet, A. 2011. Solving the probabilistic reserve selection problem. Ecol. Model. 222: 546-554. doi: 10.1016/j.ecolmodel. 2010.10.009.

Bonn, A. and K.J. Gaston. 2005. Capturing biodiversity: Selecting priority areas for conservation using different criteria. Biodivers. Conserv. 14: 1083-1100. doi: 10.1007/s10531-004-8410-6.

Briers, R.A. 2002. Incorporating connectivity in reserve selection procedures. Biol. Conserv. 10: 77-83. doi: 10.1016/S0006-3207 (01)00123-9

Cabeza, M. and A. Moilanen. 2003. Site-selection algorithms and habitat loss. Conserv. Biol. 17: 1402-1413. doi: 10.1046/j.1523-1739. 2003.01421.x.

Caro, T. M. 2003. Umbrella species: Critique and lessons from East Africa. Anim. Conserv. 6: 171-181. doi: 10.1017/S1367943003003214. Caro, T. M. and G. O'Doherty. 1999. On the use of surrogate species in conservation biology. Conserv. Biol. 13: 805-814. doi: 10.1046/j.1523-1739.1999.98338.x.

Caro, T.M., A. English, Jr., E. Fitzherbert and T. Gardener. 2004. Preliminary assessment of the flagship species concept at a small scale. Anim. Conserv. 7: 63-70. doi: 10.1017/S136794300300115X. Carvalho, S.B., J.C. Brito, R.L. Pressey, E. Crespo and H.P. Possingham. 2010. Simulating the effects of using different types of species distribution data in reserve selection. Biol. Conserv. 143: 426-438. doi:10.1016/j.biocon.2009.11.010.

Carwardine, J., K.A. Wilson, S.A. Hajkowicz, R.J. Smith, C.J. Klein, M. Watts and H.P. Possingham. 2010. Conservation planning when costs are uncertain. Conserv. Biol. 24: 1529-1537. doi: $10.1111 / \mathrm{j} .1523-1739.2010 .01535 . \mathrm{x}$ 
Chen, Y. and J. Bi. 2007. Biogeography and hotspots of amphibian species of China: Implications to reserve selection and conservation. Curr. Sci. 92: 480-489.

Church, R.L., D.M. Stoms and F.W. Davis. 1996. Reserve selection as a maximal covering location problem. Biol. Conserv. 49: 113-130. doi: 0006-3207/96.

Cowling, R. M. and R.L. Pressey. 2003. Introduction to systematic conservation planning in the Cape Floristic Region. Biol. Conserv. 112: 1-13. doi:10.1016/S0006-3207(02)00418-4.

CPAWS. 2008. (Canadian Parks and Wilderness Society). CPAWS Wilderness Conservation Vision and Approach. March 2008. http://cpaws.org/uploads/pubs/cpaws_conservation-vision.pdf [Accessed on March 11, 2013].

Dearden, P. 1995. Park literacy and conservation. Conserv. Biol. 9: 1654-1656. http://www.jstor.org/stable/2387212.

Deguise, I.E. and J.T. Kerr. 2006. Protected areas and prospects for endangered species conservation in Canada. Conserv. Biol. 20: 48-55. doi: 10.1111/j.1523-1739.2005.00274.x

Desmet, P. and R. Cowling. 2004. Using the species-area relationship to set baseline targets for conservation. Ecol. Soc. 9: 11 [online] http://www.ecologyandsociety.org/vol9/iss2/art11/

Drever, C.R., M.C. Drever and D.J.H. Sleep. 2012. Understanding rarity: A review of recent conceptual advances and implications for conservation of rare species. Forest. Chron. 88: 165-175. doi 10.5558/tfc2012-033.

Duinker, P.N., Y.F. Wiersma, W. Haider, G.T. Hvenegaard and F.K.A. Schmiegelow. 2010. Protected areas and sustainable forest management: What are we talking about? Forest. Chron. 86(2): 173-177. doi: 10.5558/tfc86173-2

Faith, D.P. and P.A. Walker. 2002. The role of trade-offs in biodiversity conservation planning: Linking local management, regional planning and global conservation efforts. J. Biosci. 27: 393-407. doi: 10.1007/BF02704968.

Flather, C.H., K.R. Wilson, D.J. Dean and W.C. McComb. 1997. Identifying gaps in conservation networks: Of indicators and uncertainty in geographic-based analyses. Ecol. Appl. 7: 532-542. http://links.jstor.org/sici?sici=105 1-0761\%28199705\%297\%3A2\% 3C53 1\%3AIGICN0\%3E2.O.CO\%3B2-P

Fleishman, E., R.F. Noss and B.R. Noon. 2006. Utility and limitations of species richness metrics for conservation planning. Ecol. Indic. 6: 543-553. doi:10.1016/j.ecolind.2005.07.005.

Game, E.T., P. Kareiva and H.P. Possingham. 2013. Six common mistakes in conservation priority setting. Conserv. Biol. 27: 480-485. doi: 10.1111/cobi.12051.

Garson, J., A. Aggarwal and S. Sarkar. 2002. Birds as surrogates for biodiversity: An analysis of a data set from southern Québec. J. Biosci. 27: 347-360. doi: 10.1007/BF02704965.

Gaston, K.J. and R.A. Fuller. 2009. The sizes of species' geographic ranges. J. Appl. Ecol. 46: 1-9. doi: 10.1111/j.1365-2664.2008.01596.x. Gaston, K.J., R.L. Pressey and C.R. Margules. 2002. Persistence and vulnerability: Retaining biodiversity in the landscape and in protected areas. J. Biosci. 27: 361-384. doi: 10.1007/BF02704966.

Gove, A.D., R.R. Dunn and J.D. Majer. 2008. The importance of species range attributes and reserve configuration for the conservation of angiosperm diversity in Western Australia. Biodivers. Conserv. 17: 817-831. doi: 10.1007/s10531-008-9321-8.

Government of British Columbia. 1996. Community Watershed Handbook, British Columbia Forest Practices Code. Government of British Columbia. Available online: https://www.for.gov.bc.ca/tasb/ legsregs/fpc/fpcguide/watrshed/watertoc.htm. [Accessed: December 9,2015$]$.

Groves, C.R. 2003. What to Conserve? Selecting Conservation Targets. In: Drafting a Conservation Blueprint: A practitioner's guide to planning for biodiversity. Island Press, Washington.

Gurd, D.B., T.D. Nudds and D.H. Rivard. 2001. Conservation of mammals in eastern North American wildlife reserves: How small is too small? Conserv. Biol. 15: 1355-1363. doi: 10.1111/j.1523-1739. 2001.00188.x.
Habib, L.D., Y.F. Wiersma and T.D. Nudds. 2003. Effects of errors in range maps on estimates of historical species richness of mammals in Canadian national parks. J. Biogeogr. 30: 375-380. doi: 10.1046/j.1365-2699.2003.00820.x.

Hansen, G.J.A., N.C. Ban, M.L. Jones, L. Kaufman, H.M. Panes, M. Yasué and A.C.J. Vincen. 2011. Hindsight in marine protected area selection: A comparison of ecological representation arising from opportunistic and systematic approaches. Biol. Conserv. 144: 1866-1875. doi: 10.1016/j.biocon.2011.04.002.

Harcourt, A.H., S.A. Parks and R. Woodroffe. 2001. Human density as an influence on species/area relationships: Double jeopardy for small African reserves? Biodivers. Conserv. 19: 1011-1026. doi: 10.1023/A:1016680327755.

Hartig, F. and M. Drechsler. 2008. The time horizon and its role in multiple species conservation planning. Biol. Conserv. 141: 2625-2631. doi: 10.1016/j.biocon.2008.07.028.

Heikkinen, R.K. 2002. Complementarity and other key criteria in the conservation of herb-rich forests in Finland. Biodivers. Conserv. 11: 1939-1958. doi: 10.1023/A:1020822509421.

Hermoso, V. and M.J. Kennard. 2012. Uncertainty in coarse conservation assessments hinders the efficient achievement of conservation goals. Biol. Conserv. 147: 52-59. doi: 10.1016/j.biocon.2012.01. Hummel, M. (ed) 1995. Protecting Canada's Endangered Spaces: An owner's manual. Key Porter Books and WWF: Toronto.

Hunter, M.L. Jr. 1993. Natural fire regimes as spatial models for managing boreal forests. Biol. Conserv. 65: 115-120. doi: 10.1016/ j.foreco.2015.09.002.

Johst, K., M. Drechsler, A.J.A. van Teeffelen, F. Hartig, C.C. Vos, S. Wissel, F. Wätzod and P. Opdam. 2011. Biodiversity conservation in dynamic landscapes: Trade-offs between number, connectivity and turnover of habitat patches. J. Appl. Ecol. 48: 1227-1235. doi/10.1111/j.1365-2664.2011.02015.x.

Jones, D.A., A.J. Hansen, K. Bly, K. Doherty, J.P. Verschuyl, J.I. Paugh, R. Carle and S. Story. 2009. Monitoring land use and cover around parks: A conceptual approach. Remote Sens. Environ. 113: 1346-1356. doi:10.1016/j.rse.2008.08.018.

Joppa, L.N., S.R. Loarie and S.L. Pimm. 2008. On the protection of "protected areas". Proceedings of the National Academy of Sciences 105: 6673-6678. doi: 10.1073/pnas.0802471105.

Justus, J. and S. Sarkar. 2002. The principle of complementarity in the design of reserve networks to conserve biodiversity: A preliminary history. J. Biosci. 27: 421-435. doi: 10.1007/BF02704970.

Justus, J., T. Fuller and S. Sarkar. 2008. Influence of representation targets on the total area of conservation-area networks. Conserv. Biol. 22: 673-682. doi: 10.1111/j.1523-1739.2008.00928.x.

Kerley, G.I.H., R.L. Pressey, R.M. Cowling, A.F. Boshoff and R. Sims-Castley. 2003. Options for the conservation of large and medium-sized mammals in the Cape Floristic Region hotspot, South Africa. Biol. Conserv. 112: 169-190. doi: 10.1016/S00063207(02)00426-3.

Kirkpatrick, J.B. 1983. An iterative method for establishing priorities for the selection of nature reserves: An example from Tasmania. Biol. Conserv. 25: 127-134. doi: 10.1016/0006-3207(83)90056-3. Conserv. Biol. 22: 610-617. doi: 10.1111/j.1523-1739.2008.00914.x. Knight, A.T., R.M. Cowling, and B.M. Campbell. 2006a. An operational model for implementing conservation action. Conserv. Biol. 20: 408-419. DOI: 10.1111/j.1523-1739.2006.00305.x.

Knight, A.T. et al. 2006b. Designing systematic conservation assessments that promote effective implementation: Best practice from South Africa. Conserv. Biol. 20: 739-750. doi: 10.1111/j.15231739.2006.00452.x.

Knight, A.T., R.M. Cowling, M. Rouget, A. Balmford, A.T., Lombard and B.M. Campbell. 2008. Knowing but not doing: Selecting priority conservation areas and the research-implementation gap.

Knight, A.T., H.S. Grantham, R.J. Smith, G.K. McGregor, H.P. Possingham and R.M. Cowling. 2011. Land managers' willingnessto-sell defines conservation opportunity for protected area expansion. Biol. Conserv. 144: 1623-2630. doi:10.1016/j.biocon.2011.07.013. 
Knoke, T. and M. Moog. 2005. Timber harvesting versus forest reserves - producer prices for open-use areas in German beech forests (Fagus sylvatica L.). Ecol. Econ. 52: 97-110. doi: 10.1016/ j.ecolecon.2004.06.012.

Knoke, T. and M. Weber. 2006. Expanding carbon stocks in existing forests - a methodological approach for coast appraisal at the enterprise level. Mitigation and Adaptation Strategies for Global Change 11: 579-605. doi: 10.1007/s11027-006-1051-1

Knoke, T. et al. 2009. Effectiveness and distributional impacts of payments for reduced carbon emissions from deforestation. Erdkunde 63: 365-384. doi: 10.3112/erdkunde.2009.04.06.

Kujala, H., M.B. Araújo, W. Thuiller and M. Cabeza. 2011. Misleading results from conventional gap analysis - messages from the warming north. Biol. Conserv. 144: 2450-2458. doi: 10.1016/j.biocon.2011.06.023.

Kukkala, A.S. and A. Moilanen. 2013. Core concepts of spatial prioritisation in systematic conservation planning. Biol. Rev. 88: 443-464. doi: 10.1111/brv.12008.

Landry, M., V.G. Thomas and T.D. Nudds. 2001. Sizes of Canadian national parks and the viability of large mammal populations: Policy implications. The George Wright Forum 18: 13-23. Permanent URL: http://www.georgewright.org/181landry.pdf

Larsen, F.W., W.R. Turner and R.A. Mittermeier. 2015. Will protection of $17 \%$ of land by 2020 be enough to safeguard biodiversity and critical ecosystem services? Oryx 49: 74-79. doi: 10.1017/ S0030605313001348.

Leroux, S.J., F.K.A. Schmiegelow, S.G. Cumming, R.B. Lesard and J. Nagy. 2007a. Accounting for system dynamics in reserve design. Ecol. Appl. 17: 1954-1966. doi: 10.1890/06-1115.1.

Leroux, S.J., F.K.A. Schmiegelow, R.B. Lessard and S.G. Cumming. 2007b. Minimum dynamic reserves: A conceptual framework for reserve sizes. Biol. Conserv. 138: 464-473. doi: 10.1016/j.biocon.2007.05.012.

Locke, H. 2013. Nature needs half: A necessary and hopeful new agenda for protected areas. Parks 19: 9-18. doi: 10.2305/ IUCN.CH.2013.PARKS-19-2.HL.en

Loehle, C. and D.J.H. Sleep. 2015. Use and application of range mapping in assessing extinction risk in Canada. Wildlife Soc. B. 39(3): 658-663. doi: 10.1002/wsb.574.

Mace, G.M. and R. Lande. 1991. Assessing extinction threats: Toward a re-evaluation of IUCN threatened species categories. Conserv. Biol. 5: 148-157. doi: 10.1111/j.1523-1739.1991.tb00119.x.

Margules, C.R., A.O. Nicholls and R.L. Pressey. 1988. Selecting networks of reserves to maximize biological diversity. Biol. Conserv. 43: 63-76. doi: 10.1016/0006-3207(88)90078-X.

Margules, C.R. and R.L. Pressey. 2000. Systematic conservation planning. Nature 405: 243-253. doi:10.1038/35012251.

Margules, C.R., R.L. Pressey and P.H. Williams. 2002. Representing biodiversity: Data and procedures for identifying priority areas for conservation. J. Biosci. 27: 309-326. doi: 10.1007/BF02704962.

McCarthy, M.A., C.J. Thompson and N.S.G. Williams. 2006. Logic for designing nature reserves for multiple species. Am. Nat. 167: 717-727. doi: 10.1086/503058.

McCoy, E.D. and H.R. Mushinksy. 2007. Estimates of minimum patch size depend on the method of estimation and the condition of the habitat. Ecol. 88: 1401-1407. doi: 10.1890/06-1188.

McKee, J.K., P.W. Sciulli, C.D. Fooce and T.A. Waite. 2004. Forecasting global biodiversity threats associates with human population growth. Biol. Conserv. 115(1): 161-164. doi:10.1016/S0006-3207 (03)00099-5.

McNeely, J. and K. Miller. (eds) 1984. National Parks Conservation and Development: The Role of Protected Areas in Sustaining Society. Proceedings of the World Congress on National Parks. Smithsonian Institution Press: Washington. ISBN: 0-87474-663-9.

Meir, E., S. Andelman and H.P. Possingham. 2004. Does conservation planning matter in a dynamic and uncertain world? Ecol. Lett. 7: 615-622. doi: 10.1111/j.1461-0248.2004.00624.x.
Mendenhall, C.D., D.S. Karp, C.F.J. Meyer, E.A. Hadley and G.C. Daily. 2014. Predicting biodiversity change and averting collapse in agricultural landscapes. Nature 509: 23-217. doi: 10.1038/ nature13139.

Moilanen, A. and B.A. Wintle. 2007. The boundary-quality penalty: A quantitative method for approximating species responses to fragmentation in reserve selection. Conserv. Biol. 21: 355-364. doi: 10.1111/j.1523-1739.2006.00625.x.

Moilanen, A., K.A. Wilson and H. Possingham. (eds) 2009. Spatial conservation prioritization: Quantitative methods and computational tools. Oxford University Press, Toronto

NCASI. 2011. (National Council for Air and Stream Improvement, Inc.). The role of forest management in maintaining conservation values. Technical Bulletin No. 983. Research Triangle Park, NC.

Noss, R.F. 1993. A conservation plan for the Oregon Coast Range: some preliminary suggestions. Nat. Area. J. 13: 276-290.

Noss, R.F. 1996. Protected areas: How much is enough? In: National Parks and Protected Areas: Their Role in Environmental Protection (ed. R.G. Wright), pp. 91-120. Blackwell Science, Cambridge.

Noss, R.F. et al. 2012. Bolder thinking for conservation. Conserv. Biol. 26: 1-4. doi: 10.1111/j.1523-1739.2011.01738.x.

Parks, S.A. and A.H. Harcourt. 2002. Reserve size, local human density, and mammalian extinctions in U.S. protected areas. Conserv. Biol. 16: 800-808. doi: 10.1046/j.1523-1739.2002.00288.x.

Perhans, K., C. Kindstand, M. Boman, L.B. Djupström, L. Gustafsson, L. Mattsson, L.M. Schroeder, J. Weslien and S. Wikberg. 2008. Conservation goals and the relative importance of costs and benefits in reserve selection. Conserv. Biol. 22: 1331-1339. doi: 10.1111/j.1523-1739.2008.00976.x.

Pickett, S.T.A. and J.N. Thompson. 1978. Patch dynamics and the design of nature reserves. Biol. Conserv. 13: 27-37. doi: 10.1016/0006-3207(78)90016-2.

Pressey, R.L. and M.C. Bottrill. 2009. Approaches to landscapeand seascape-scale conservation planning: Convergence, contrasts and challenges. Oryx 43: 464-475. doi:10.1017/S0030605309990500. Pressey, R.L., M. Cabeza, M.E. Watts, R.M. Cowling and K.A.Wilson. 2007. Conservation planning in a changing world. Trends Ecol. Evol. 22: 583-592. doi: 10.1016/j.tree.2007.10.001.

Pressey, R.L., R.M. Cowling and M. Rouget. 2003. Formulating conservation targets for biodiversity pattern and process in the Cape Floristic Region, South Africa. Biol. Conserv. 112: 99-127. doi:10.1016/S0006-3207(02)00424-X.

Pressey, R.L. and V.S. Logan. 1998. Size of selection units for future reserves and its influence on actual vs. targeted representation of features: A case study in western New South Wales. Biol. Conserv. 85: 305-319. doi: 10.1016/S0006-3207(97)00146-8.

Pressey, R.L. and A.O. Nicholls. 1989. Application of a numerical algorithm to the selection of reserves in semi-arid New South Wales. Biol. Conserv. 50: 263-278. doi: 10.1016/0006-3207(89)90013-X. Reed, D.H., J.J. O'Grady, B.W. Brook, J.D. Ballou and R. Frankham. 2003. Estimates of minimum viable population sizes for vertebrates and factors influencing those estimates. Biol. Conserv. 113: 23-34. doi: 10.1016/S0006-3207(02)00346-4.

ReVelle, C.S., J.C. Williams and J.J. Boland. 2002. Counterpart models in facility location science and reserve selection science. Environ. Model. Assess. 7: 71-80. doi: 10.1023/A:1015641514293.

Roberge, J.-M., G. Mikusiński and S. Svensson. 2008. The whitebacked woodpecker: Umbrella species for forest conservation planning? Biodiver. Conserv. 17: 2479-2494. doi: 10.1007/s10531-0089394-4.

Rodrigues, A.S.L. and K.J. Gaston. 2002. Rarity and conservation planning across geopolitical units. Conserv. Biol. 16: 674-682. doi: 10.1046/j.1523-1739.2002.00455.x.

Rodrigues, A.S.L. and T.M. Brooks. 2007. Shortcuts for biodiversity conservation planning: The effectiveness of surrogates. Annu. Rev. Ecol. Syst. 38: 713-737. doi: 10.1146/annurev.ecolsys.38. 091206.095737 . 
Rodrigues, A.S.L., K.J. Gaston and R.D. Gregory. 2000a. Using presence-absence data to establish reserve selection procedures that are robust to temporal species turnover. Proceedings of the Royal Society London B. 267: 897-902. doi: 10.1098/rspb.2000.1087.

Rodrigues, A.S.L., R.D. Gregory and K.J. Gaston. 2000b. Robustness of reserve selection procedures under temporal species turnover. Proceedings of the Royal Society London B. 267: 49-55. doi: 10.1098/rspb.2000.0965.

Rodrigues, A.S., J.O. Cerdeira and K.J. Gaston. 2000c. Flexibility, efficiency, and accountability: Adapting reserve selection algorithms to more complex conservation problems. Ecography 23: 565-574. doi: 10.1111/j.1600-0587.2000.tb00175.x.

Rondinini, C., K.A. Wilson, L. Boitani, H. Grantham and H.P. Possingham. 2006. Tradeoffs of different types of species occurrence data for use in systematic conservation planning. Ecol. Lett. 9: 1136-1145. doi: 10.1111/j.1461-0248.2006.00970.x.

Rubio, L., M. Rodrígues-Freire, M.C. Mateo-Sánchez, C. Estreguil and S. Saura. 2012. Sustaining forest landscape connectivity under different land cover change scenarios. Forest Syst. 21: 223-235. doi: 10.5424/fs/2012212-02568.

Runte, A. 2010. National parks: The American experience. Taylor Trade Publications, Toronto.

Ryti, R.T. 1992. Effect of the focal taxon on the selection of nature reserves. Ecol. Appl. 2: 404-410. doi: 10.2307/1941875.

Saetersdal, M., J.M. Line and H.J.B. Birks. 1993. How to maximize biodiversity in nature reserve selection: Vascular plants and breeding birds in deciduous woodlots, western Norway. Biol. Conserv. 66: 131-138. http://discovery.ucl.ac.uk/id/eprint/165809

Sarkar, S. 2005. Biodiversity and Environmental Philosophy - An Introduction. Cambridge University Press, New York.

Sarkar, S. 2012. Complementarity and the selection of nature reserves: Algorithms and the origins of conservation planning, 1980-1995. Arch. Hist. Exact Sci. 66: 397-426. doi: 10.1007/s00407012-0097-6.

Sarkar, S. and P. Illoldi-Rangel. 2010. Systematic conservation planning: An updated protocol. Nat. Conservacao 8: 19-26. doi: 10.4322/natcon.00801003.

Schneider, R.R., G. Hauer, W.L. Adamowicz and S. Boutin. 2010. Triage for conserving populations of threatened species: The case of woodland caribou in Alberta. Biol. Conserv. 143: 1603-1611. doi: 10.1016/j.biocon.2010.04.002.

Simaika, J.P. and M.J. Samways. 2009. Reserve selection using Red Listed taxa in three global biodiversity hotspots: Dragonflies in South Africa. Biol. Conserv. 142: 638-651. doi: 10.1016/j.biocon.2008.11.012.

Smith, R.J., E. Di Minin, S. Linke, D.B. Segan and H.P. Possingham. 2010. An approach for ensuring minimum protected area size in systematic conservation planning. Biol. Conserv. 143: 2525-2531. doi:10.1016/j.biocon.2010.06.019.

Solomon, M., A.S. van Jaarsveld, H.C. Biggs and M.H. Knight. 2003. Conservation targets for viable species assemblages? Biodivers. Conserv. 12: 2435-2441. doi: 10.1023/A:1025805731366.

Soulé, M.E. and M.A. Sanjayan. 1998. Conservation targets: Do they help? Science 279: 2106-2108. http://www.jstor.org/stable/ 2896256

Spring, D., J. Baum, R. Mac Nally, M. Mackenzie, A. SanchezAzofeifa and J.R. Thomson. 2010. Building a regionally connected reserve network in a changing and uncertain world. Conserv. Biol. 24: 691-700. doi: 10.1111/j.1523-1739.2009.01419.x.

Strange, N., B.J. Thorsen and J. Bladt. 2006. Optimal reserve selection in a dynamic world. Biol. Conserv. 131: 33-41. doi: 10.1016/ j.biocon.2006.02.002.

Strittholt, J.R. and S.J. Leroux. 2012. A methodological framework for protected areas planning in support of the Canadian Boreal For- est Agreement. Iteration 1. September 2012. Canadian Boreal Forest Agreement, Ottawa ON. Available at http://cbfa-efbc.ca/wp-content/uploads/2014/12/CBFAProtectedAreas_guidelines_EN1.pdf [Accessed 14 December 2015].

Sullivan, B.L., C.L. Wood, M.J. Iliff, R.E. Bonney, D. Fink and S. Kelling. 2009. eBird: A citizen-based bird observation network in the biological sciences. Biol. Conserv. 142: 2282-2292. doi: 10.1016/j.biocon.2009.05.006

Svancara, L.K., R. Brannon, J.M. Scott, C.R. Groves, R.F. Noss and R.L. Pressey. 2005. Policy-driven vs. evidence-based conservation: A review of political targets and biological needs. Bio Sci. 55: 989-995. doi: 10.1641/0006-3568(2005)055[0989:PVECAR]2.0.C.

Tear, T.H. et al. 2005. How much is enough? The recurrent problem of setting measurable objectives in conservation. Bio Sci. 55: 835-849. doi: 10.1641/0006-3568(2005)055[0835:HMIETR]2.0.CO;2. Vanderkam, R.P.D., Y.F. Wiersma and D.J. King. 2007. Heuristic algorithms vs. linear programs for designing efficient conservation reserve networks: Evaluation of solution optimality and processing time. Biol. Conserv. 137: 349-358. doi: 10.1016/j.biocon.2007.02.018. Van Teeffelen, A.J.A., C.C. Vos, and P. Opdam. 2012. Species in a dynamic world: Consequences of habitat network dynamics on conservation planning. Biol. Conserv. 153: 239-253. doi:10.1016/j.biocon.2012.05.001.

Venter, O. et al. 2014. Targeting local protected area expansion for imperiled biodiversity. PLoS Biology 12, e1001891. doi:10.1371/ journal.pbio.1001891.

Warman, L.D., D.M. Forsyth, A.R.E. Sinclair, K. Freemark, H.D. Moore, T.W. Barrett, R.L. Pressey and D. White 2004. Species distribution, surrogacy, and important conservation regions in Canada. Ecol. Lett. 7: 374-379. doi: 10.1111/j.1461-0248.2004.00590.x.

WCED. 1987. (World Commission on Environment and Development). Our Common Future.Oxford University Press, Oxford, UK. Wells, J., D. Childs, F. Reid, D. Smith, M. Darveau and V. Courtois. 2014. Boreal Birds Need Half: Maintaining North America's Bird Nursery and Why it Matters. Boreal Songbird Initiative, Seattle, Washington, Ducks Unlimited Inc., Memphis, Tennessee, and Ducks Unlimited Canada, Stonewall, Manitoba. Available at: http://www.borealbirds.org/sites/default/files/pubs/birdsneedhalf_0.pdf [Accessed 14 December 2015].

Wiersma, Y.F. and T.D. Nudds. 2006. Conservation targets for viable species assemblages in Canada: Are percentage targets appropriate? Biodivers. Conserv. 15: 4555-4567. doi: 10.1007/s10531-0055819-5.

Wiersma, Y.F. and C. Simonson. 2010. Parks as islands: Species loss in Canadian national parks. Parks Science 27: 70-77.

Wiersma, Y.F., T.D. Nudds and D.H. Rivard. 2004. Models to distinguish effects of landscape patterns and human population pressures associated with species loss in Canadian national parks. Landscape Ecol. 19: 773-786. doi:10.1007/s10980-005-3989-y.

Wilhere, G.F., L.A. Maguire, J.M. Scott, J.L. Rachlow, D.D. Goble and L.K. Svancara. 2012. Conflation of values and science: Response to Noss et al. Conserv. Biol. 26: 943-944. doi: 10.1111/ j.1523-1739.2012.01900.x.

Williams J.C., C.S. ReVille and S.A. Levin. 2004. Using mathematical optimization models to design nature reserves. Front. Ecol. Environ. 2: 98-105. doi: 10.1890/1540-9295(2004)002[0098:UMOMTD] 2.0.CO;2.

Williams, P.H., C.R. Margules and D.W. Hilbert. 2002. Data requirements and data sources for biodiversity priority area selection. J. Biosci. 27: 327-338. doi: 10.1007/BF02704963.

Wilson, K., R.L. Pressey, A. Newton, M. Burgman, H. Possingham and C. Weston. 2005. Measuring and incorporating vulnerability into conservation planning. Environ. Manage. 35: 527-543. doi: 10.1007/s00267-004-0095-9. 


\begin{tabular}{llrc} 
AuthorPrimary & Year & PeriodicalTitle & Vol Issue \\
\hline Alagador \& Cerdeira & 2007 Biological Conservation & 137 & 2 \\
Andrew et al. & 2011 Biological Conservation & 144 & 12 \\
Andrew et al. & 2012 Biological Conservation & 146 & 1 \\
Araujo & 1999 Diversity and Distributions & 5 & 4 \\
Arponen et al. & 2007 Conservation Biology & 21 & 2 \\
Averill-Murray & 2013 Herpetological Conservation and Biodiversity & 8 & 1 \\
Barbosa et L. & 2010 Conservation Biolgy & 24 & 5 \\
Beazley et al. & 2005 Ecological Applications & 15 & 6 \\
Bedward et al. & 1992 Biological Conservation & 62 & 2 \\
Belbin & 1993 Biological Conservation & 66 & 3 \\
Betrus et al. & 2005 J Environmental Management & 74 & 1 \\
Bino et al. & 2013 Austral Ecology & 38 & 4 \\
Bonn \& Gaston & 2005 Biodiversity and Conservation & 14 & 5 \\
Boyce et al. & 2002 Journal of Bioscience & 27 & 4 \\
Briers & 2002 Biological Conservation & 103 & 1 \\
Bruinderink et al. & 2003 Conservation Biology & 17 & 2 \\
Burns et al. & 2013 Biological Conservation & 158 & \\
Cabeza & 2003 Ecology Letters & 6 & 7 \\
Camm et al. & 2002 Operations Research & 50 & 6 \\
Cardillo et al. & 2006 PNAS & 103 & 11 \\
Caro & 2003 Animal Conservation & 6 & 2 \\
Carroll et al. & 2001 Ecological Applications & 11 & 4 \\
Carvalho et al. & 2010 Biological Conservation & 143 & 2 \\
Carwardine et al. & 2007 Biodiversity and Conservation & 16 & 1 \\
Ceballos \& Ehrlich & 2006 PNAS & 103 & 51 \\
Chen \& Bi & 2007 Current Science & 92 & 4 \\
Clark\&Slusher & 2000 Landscape Ecology & 15 & 1 \\
Cowling et al. & 2003 Biological Conservation & 112 & $1-2$ \\
Cumming et al. & 1996 Ecography & 19 & 2 \\
D'Amen & 2013 Animal Conservation & 16 & 4 \\
Desmet \& Cowling & 2004 Ecology \& Society & 9 & 2 \\
Di Minin & 2013 PLoS One & 8 & 8
\end{tabular}


Dobson et al.

Dockerty et al.

Dunk et al.

Faith \& Walker

Faleiro

Faleiro \& Loyola

Fleishman et al.

Freudenburger et al.

Galetti et al.

Gao et al

Gordon et al.

Gove et al.

Grant \& Samways

Grelle et al.

Hannah et al.

Harris et al.

Heikkinen

Hermoso \& Kennard

Hernandez-Manrique et al.

Hoctor et al.

Hornberg et al.

Huber et al.

Jaffre et al.

Jantke et al.

Jenkins et al.

Justus et al.

Kareksela et al.

Kati et al.

Kerley et al.

Klein et al.

Kohlmann et al.

Krupnick \& Kress

Lachat \& Butler
2001 Ecological Applications

2003 Global Environmental Change

2006 Diversity and Distributions

2002 Journal of Bioscience

2013 Biological Conservation

2013 Diversity and Distributions

2001 Ecological Applications

2013 Biodiversity \&Conservation

2009 Biological Conservation

2013 Landscape Ecology

2013 Ecological Modelling

2008 Biodiversity and Conservation

2011 Biological Conservation

2010 Natureza \& Conservacoa

2007 Frontiers in Ecology and Environment

2014 Estuarine, Coastal and Shelf Science

2002 Biodiversity and Conservation

2012 Biological Conservation

2012 Biodiversity and Conservation

2000 Conservation Biology

1998 BioScience

2010 The Professional Geographer

1998 Biodiversity and Conservation

2013 Environmental Conservation

2013 PNAS

2008 Conservation Biology

2013 Conservation Biology

2004 Biological Conservation

2003 Biological Conservation

2009 Ecological Applications

2007 Zootaxa

2003 Biodiversity and Conservation

2009 Environmental Management

$\begin{array}{rc}11 & 4 \\ 13 & 2 \\ 12 & 4 \\ 27 & 4 \\ 158 & - \\ 19 & 8 \\ 11 & 5 \\ 22 & 5 \\ 142 & 6 \\ 28 & 10 \\ 249 & - \\ 17 & 4 \\ 144 & 2 \\ 8 & 1 \\ 5 & 3 \\ 150 & \\ 11 & 11 \\ 147 & 1 \\ 21 & 8 \\ 14 & 4 \\ 48 & 10 \\ 62 & 3 \\ 7 & 1 \\ 40 & 1 \\ 110 & 28 \\ 22 & 3 \\ 27 & 6 \\ 120 & 4 \\ 112 & 1-2 \\ 19 & 1 \\ 1457 & \\ 12 & 11 \\ 44 & 1\end{array}$


Landry et al. Lentini et al.

Leroux et al.

Leroux et al.

Levin et al.

Loyola et al.

Loyola et al.

Maiorano et al.

Marfil-Daza

Margules et al.

Marignani \& Blasi

Martin \& Ferrier

Mateo et al.

McCarthy et al.

McCoy \& Mushinsky

Mikkonen \& Moilanen

Moilanen \& Wintle

Moilanen\&Wintle

Mokany et al.

Nicholson et al.

Parks \& Harcourt

Pearce et al.

Pressey \& Logan

Pressey \& Logan `

Pressey \& Nicholls

Pressey \&Nicholls

Pressey et al.

Pressey etal.

Pryke and Samways

Ramage

Rayfield et al.

Rayfield et al.

Reyers et al.
2001 The George Wright Forum

2013 Conservation Biology

2007a Ecological Applications

2007b Biological Conservation

2013 Biological Conservation

2013 Biodiversity \&Conservation

2007 Diversity and Distributions

2006 Biological Conservation

2013 Animal Conservation

1988 Biological Conservation

2012 Biodiversity and Conservation

2013 Ardeola

2013 Biological Conservation

2006 The American Naturalist

2007 Ecology

2013 Environmental Science andolicy

2007 Conservation Biology

2006 Biological Conservation

2013 Journal of Applied Ecology

2006 Ecology Letters

2002 Conservation Biology

2008 Biological Conservation

1995 Conservation Biology

1998 Biological Conservation

1989b Biological Conservation

1989 Biological Conservation

2000 Biological Conservation

2003 Biological Conservation

2008 Biodiversity and Conservation

2013 Biodiversity and Cinservation

2008 Biological Conservation

2009 ecological Modelling

2000 Proc Royal Soc B
18

158

$22 \quad 2$

134

1334

$16 \quad 1$

$43 \quad 1$

$21 \quad 7$

$60 \quad 1$

160

$167 \quad 5$

$88 \quad 6$

27

$21 \quad 2$

1293

$50 \quad 2$

99

163

$141 \quad 4$

96

853

$50 \quad 1-4$

$50 \quad 1-4$

$96 \quad 1$

$112 \quad 1-2$

$17 \quad 12$

223

$141 \quad 2$

$220 \quad 5$

$267 \quad 1442$ 
Rogers et al.

Rothley \& Rae

Rouget et al.

Rouget et al.

Rubio et al.

Sarakinos et al.

Sarkar et al.

Schleupner \& Schneider

Schneider et al.

Scott et al.

Sergio et al.

Shriner et al.

Siitonen et al.

Simaika \& Samways

Simaika et al.

Smith et al.

Solomon et al.

Spring et al.

Steinitz et al.

Vellak et al.

Villalobos et al.

Vimal et al.

Warman et al.

Wiersma \& Nudds

Wiersma \& Nudds

Wilhere et al.

Williams et al.

Wu et al.
2013 Biological Conservation

2005 Env Monitoring and Assessment

2003 Diversity and Distributions

2003 Biological Conservation

2012 Forest Systems

2001 Biodiversity and Conservation

2008 Biodiversity and Conservation

2013 Land Use Policy

2007 PLoS One

2001 Biodiversity and Conservation

2006 J Applied Ecology

2006 Ecological Applications

2002 Conservation Biology

2009 Biological Conservation

2013 Biological Conservation

2010 Biological Conservation

2003 Biodiversity and Conservation

2010 Conservation Biology

2005 Conservation Biology

2010 Biodiversity and Conservation

2013 Biological Conservation

2011 Biodiversity and Conservation

2004 Conservation Biology

2006 Biodiversity and Conservation

2009 Biological Conservation

2008 Biological Conservation

1996 Conservation Biology

2013 Zoological Studies

$\begin{array}{rc}110 & 5 \\ 10 & 2 \\ 9 & 3 \\ 1112 & 1-2 \\ 21 & 2 \\ 10 & 9 \\ 17 & 10 \\ 30 & 1 \\ 2 & 11 \\ 10 & 8 \\ 43 & 6 \\ 16 & 5 \\ 16 & 5 \\ 142 & 3 \\ 157 & \\ 143 & 11 \\ 12 & 12 \\ 24 & 3 \\ 19 & 6 \\ 19 & 5 \\ 158 & \\ 20 & 3 \\ 18 & 3 \\ 15 & 14 \\ 142 & 8 \\ 141 & 3 \\ 10 & 1 \\ 52 & 1\end{array}$


Page

254-262

2891-2901

97-107

151-163

527-533

$1-15$

1378-1387

2192-2208

115-125

223-230

79-87

393-404

1083-1100

385-392

77-83

549-557

14-25

665-672

946-955+1076

4157-4161

171-181

961-980

426-438

245-258

19374-19379

480-489

75-84

191-216

162-180

370-378

11

e71788

\section{ArticleTitle}

Designing spatially-explicit reserve networks in the presence of mandatory sites

Patterns of protection and threats along productivity gradients in Canada

Identification of de facto protected areas in boreal Canada

Distribution patterns of biodiversity and the design of a representative reserve network in Portugal

Area-based refinement for selection of reserve sites with the benefit-function approach

Conserving population linkages for the Mojave desert tortoise (Gopherus agassizii)

Use of coarse-resolution models of species' distributions to guide local conservation inferences

Biodiversity considerations in conservation system planning: Map-based approach for Nova Scotia, Can: A new approach for selecting fully representative reserve networks: addressing efficiency, reserve desi Environmental representativeness: Regional partitioning and reserve selection

Cross-taxonomic potential and spatial transferability of an umbrella species index Improving bioregional frameworks for conservation by including mammal distributions

Capturing biodiversity: Selecting priority areas for conservation using different criteria

Bet-hedging applications for conservation

Incorporating connectivity into reserve selection procedures

Designing a coherent ecological network for large mammals in northwestern Europe

A modeling framework for life history-based conservation planning

Habitat loss and connectivity of reserve networks in probability approaches to reserve design

Nature reserve site selection to maximize expected species covered

Latent extinction risk and the future battlegrounds of mammal conservation

Umbrella species: Critique and lessons from East Africa

Carnivores as focal species for conservation planning in the Rocky Mountain region

Simulating the effects of using different types of species distribution data in reserve selection

Conservation planning with irreplaceability: Does the method matter?

Global mammal distributions, biodiversity hotspots, and conservation

Biogeography and hotspots of amphibian species of China: Implications to reserve selection and conser Using spatial analysis to drive reserve design: A case study of a national wildlife refuge in Indiana and II A conservation plan for a global biodiversity hotspot - The Cape Floristic Region, South Africa Boreal mixedwood forests may have no "representative" areas: Some implications for reserve design Protected areas and insect conservation: Questioning the effectiveness of Natura 2000 network for sa Using the species-area relationship to set baseline targets for conservation

Creating larger and better connected protected areas enhances the persistence of big game species in 
1019-1026

125-135

434-442

393-407

248-257

977-987

1489-1501

1255-1281

1229-1241

1949-1959

19-25

817-831

772-781

46-53

131-138

45-577

1939-1958

52-59

2127-2137

984-1000

795-802

409-425

109-135

37-47

E2602-2610

673-682

1294-1303

471-480

169-190

206-217

1-34

2237-2253

105-118
Synoptic tinkering: Integrating strategies for large-scale conservation

Climate change and nature reserves: Examining the potential impacts, with examples from Great Britair Evaluating reserves for species richness and representation in northern California

The role of trade-offs in biodiversity conservation planning: Linking local management, regional plannin! Defining spatial conservation priorities in the face of land-use and climate change

Socioeconomic and political trade-offs in biodiversity conservation: A case study of the Cerrado Biodivt Empirical validation of a method for umbrella species selection

Nature conservation: Priority-setting needs a global change

Priority areas for the conservation of Atlantic forest large mammals

Identifying functionally connected habitat compartments with a novel regionalization technique

Simulating the value of collaboration in multi-actor conservation planning

The importance of species range attributes and reserve configuration for the conservation of angiospe

Micro-hotspot determination and buffer zone value for Odonata in a globally significant biosphere reser Reserve selection based on vegetation in the Brazilian Atlantic Forest

Protected area needs in a changing climate

Setting conservation targets for sandy beach ecosystems

Complementarity and other key criteria in the conservation of herb-rich forests in Finland

Uncertainty in coarse conservation assessments hinders the efficient achievement of conservation goa Using local autocorrelation analysis to identify conservation areas: An example considering threatened Indentifying a linked reserve system using a regional landscape approach: The Florida ecological networ Boreal swamp forests: Biodiversity 'hotspots' in an impoverished forest landscape

Boundaries make a difference: The effects of spatial and temporal parameters on conservation plannins Threatened plants of New Caledonia: Is the system of protected areas adequate?

Benefits of earth observation data for conservation planning in the case of European wetland biodivers Global patterns of terrestrial vertebrate diversity and conservation.

Influence of representation targets on the total area of conservation-area networks

Use of inverse spatial conservation prioritization to avoid biological diversity loss outside protected are Hotspots, complementarity or representativeness? Designing optimal small-scale reserves for biodivers Options for the conservation of large and medium-sized mammals in the Cape Floristic Region hotspot, Incorporating ecological and evolutionary processes into continental-scale conservation planning

Biodiversity, conservation, and hotspot atlas of Costa Rica: A dung beetle perspective (Coleoptera: Sci Hotspots and ecoregions: A test of conservation priorities using taxonomic data

Identifying conservation and restoration priorities for saproxylic and old-growth forest species: A case 
13-237

796-807

1954-1966

464-473

371-383

483-495

389-396

455-473

60-68

63-76

1853-1864

15-28

150-161

717-727

1401-1407

11-20

355-364

427-434

519-527

1049-1060

800-808

908-924

1506-1517

305-319

263-278

199-218

55-82

99-127

3027-3043

789-801

438-449

725-733

505-513
Sizes of Canadian national parks and the viability of large mammal populations: policy implications Effect of planning for connectivity on linear reserve networks

Accounting for system dynamics in reserve design

Minimum dynamic reserves: A framework for determining reserve size in ecosystems structured by larc A framework for systematic conservation planning and management of Mediterranean landscapes

A straightforward conceptual approach for evaluating spatial conservation priorities under climate char Endemic vertebrates are the most effective surrogates for identifying conservation priorities among $\mathrm{Br}$ Gap analysis of terrestrial vertebrates in Italy: Priorities for conservation planning in a human dominate Do hot spots of breeding birds serve as surrogate hot spots of wintering birds? An example from centr Selecting networks of reserves to maximise biological diversity

Looking for important plant areas: Selection based on criteria, complementarity, or both?

Assessing biodiversity distribution using diurnal raptors in Andalusia, southern Spain

A new spin on a compositionalist predictive modelling framework for conservation planning: A tropical c Logic for designing nature reserves for multiple species

Estimates of minimum patch size depend on the method of estimation and the condition of the habitat Identification of top priority areas and management landscapes from a national Natura 2000 network

The boundary-quality penalty: A quantitative method for approximating species responses to fragment Uncertainty analysis favours selection of spatially aggregated reserve networks

Comparing habitat configuration strategies for retaining biodiversity under climate change

A new method for conservation planning for the persistence of multiple species

Reserve size, local human density, and mammalian extinctions in U.S. protected areas

Prioritizing avian conservation areas for the Yellowstone to Yukon Region of North America

Reserve coverage and requirements in relation to partitioning and generalization of land classes: Analys Size of selection units for future reserves and its influence on actual vs targeted representation of feat Application of a numerical algorithm to the selection of reserves in semi-arid New South Wales Efficiency in conservation evaluation: Scoring versus iterative approaches

Using abiotic data for conservation assessments over extensive regions: Quantitative methods applied Formulating conservation targets for biodiversity pattern and process in the Cape Floristic Region, Sou Conservation of invertebrate biodiversity on a mountain in a global biodiversity hotspot, Cape Floral Re Optimized Floating Refugia: A new strategy for species conservation in production forest landscapes Comparing static versus dynamic protected areas in the Québec boreal forest Incorporating consumer-resource spatial interactions in reserve design

Complementarity as a biodiversity indicator strategy 
1750-1755

107-113

191-210

129-145

223-235

1419-1472

2495-2511

604-614

e1171

1297-1301

1049-1055

1660-1673

1398-1408

638-651

245-254

2525-2531

2435-2441

691-700

1978-1988

1353-1364

313-320

531-543

656-666

4555-4567

1639-1646

770-781

155-174

29
Centennial-scale fluctuations and regional complexity characterize Pacific salmon population dynamics , Working backwards to move forwards: Graph-based connectivity metrics for reserve network selection Identifying spatial components of ecological and evolutionary processes for regional conservation planr The current configuration of protected areas in the Cape Floristic Region, South Africa - Reservation bi: Sustaining forest landscape connectivity under different land cover change scenarios

Area prioritization for biodiversity conservation in Québec on the basis of species distributions: A prelir Conservation of freshwater fish resources of India: New approaches, assessment and challenges

Allocation of European wetland restoration options for systematic conservation planning

Prior exposure to uninfected mosquitoes enhances mortality in naturally-transmitted West Nile virus int Representation of natural vegetation in protected areas: Capturing the geographic range

Ecologically justified charisma: Preservation of top predators delivers biodiversity conservation

Reserve networks based on richness hotspots and representation vary with scale

Method for selection of old-forest reserves

Reserve selection using Red Listed taxa in three global biodiversity hotspots: Dragonflies in South Afric Continental-scale conservation prioritization of African dragonflies

An approach for ensuring minimum protected area size in systematic conservation planning

Conservation targets for viable species assemblages?

Building a regionally connected reserve network in a changing and uncertain world

Predicting regional patterns of similarity in species composition for conservation planning

Vascular plant and bryophytes species representation in the protected areas network on the national s

Range-diversity plots for conservation assessments: Using richness and rarity in priority setting

The sensitivity of gap analysis to conservation targets

Sensitivity of systematic reserve selection to decisions about scale, biological data, and targets: Case : Conservation targets for viable species assemblages in Canada: are percentage targets appropriate?

Efficiency and effectiveness in representative reserve design in Canada: The contribution of existing pr Average optimacity: An index to guide site prioritization for biodiversity conservation

A comparison of richness hotspots, rarity hotspots, and complementary areas for conserving diversity Hotspot analysis of Taiwanese breeding birds to determine gaps in the protected area network 
ada

gn and land suitability with an iterative analysis

vation

linois (USA)

ıproxylic beetles in Italy

I the Maputaland-Pondoland-Albany biodiversity hotspot 
1

$g$ and global conservation efforts

ersity Hotspot, Brazil

rm diversity in Western Australia

ve

Is

invertebrate species in Spain

k

y

ity

Ias

ity conservation

South Africa

arabaeidae: Scarabaeinae)

study in Switzerland 
je disturbances

Ige

azilian ecoregions

d landscape

-al Spain

zase study in Ecuador

ation in reserve selection

sis for western New South Wales

tures: A case study in western New South Wales

across New South Wales, Australia

th Africa

gion 
over the past five centuries

ling in the Cape Floristic Region, South Africa

as and representation of biodiversity patterns and processes

ninary analysis

fection

:a

cale

study from southern British Columbia

otected areas

of British birds 